\title{
Estudio arqueométrico de muestras de cerámica de la Amazonía peruana, cronología-estilística y la dinámica cultural
}

Artículos originales: ARQUEOLOGÍA

Recibido: 28/04/2021

Aprobado: 12/06/2021

Publicado: 14/10/2021
Ana Clemencia Mujica Baquerizo

Universidad Nacional Mayor de San Marcos

ana.mujica@unmsm.edu.pe

Daniel Morales Chocano

Universidad Nacional Mayor de San Marcos dmoralesc1@unmsm.edu.pe

Irvin Navarro Amaro

Universidad Nacional Mayor de San Marcos

i.navarro.arq@hotmail.com

\section{RESUMEN}

El uso de la arqueometría como método de análisis aplicado a la cerámica arqueológica de la Amazonía peruana, nos permite confirmar y conocer con precisión científica los componentes químicos y mineralógicos que se incluyen como materia prima en la elaboración y producción de la cerámica, lo que a su vez nos dan derroteros de la ubicación geográfica de las fuentes de origen de las canteras. El análisis arqueométrico también nos permite comprobar que los temperantes o desgrasantes de origen orgánico, como la «apacharana» o la esponja de agua (cauchi), usado por los nativos amazónicos tendría un alto porcentaje mineralógico de aluminosilicatos. La importancia de esta investigación es, además, corroborar varias hipótesis, no solo sobre los componentes mineralógicos en el proceso de elaboración de la cerámica, sino también para conocer otros aspectos sociales importantes sobre la cronología y la dinámica del proceso de interacción entre las sociedades prehistóricas amazónicas.

Palabras Clave: Arqueología amazónica, cerámica, arqueometría, componentes mineralógicos, estilos, cronología e interacción social.

\section{Archaeometric study of ceramic samples from the peruvian amazon, chronology-stylistics and cultural dynamics}

\begin{abstract}
Archaeometry is applied to analyze archaeological ceramics in the Peruvian Amazon. This scientific method allows us to identify its chemical and mineralogical components, just as the raw materials used to produce ceramics. At the same time, it gives us directions about the geographical location of the quarries. The archaeometric analysis let us verify that tempers or organic origin degreasers, as 'apacharana' or 'cauchi' water sponge, used by Amazonian natives, could have a high mineralogical percentage of aluminosilicates. This research corroborates several hypotheses about mineralogical components in the ceramic making process and other social aspects about chronology and dynamics of interaction processes between prehistoric Amazonian societies.
\end{abstract}

KeYwords: Amazonian archeology, ceramics, archeometry, mineralogical components, styles, chronology and social interaction. 


\section{Introducción}

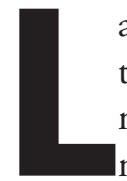

a arqueología tiene una trayectoria de investigaciones interdisciplinarias, utilizando los métodos y técnicas analíticas de las ciencias naturales y físicas, en base a ello, la arqueología ha logrado mayor profundidad y veracidad de los conocimientos acerca de los problemas socio-culturales que se investiga sobre las sociedades del pasado. Sin embargo, aún hoy algunos arqueólogos se resisten al uso y colaboración interdisciplinaria con la arqueometría.

«La Arqueometría es el campo interdisciplinario en el que las investigaciones arqueológicas utilizan técnicas y métodos desarrollados en el ámbito de las ciencias naturales y exactas, para analizar los restos de actividades de las poblaciones que nos precedieron, obteniendo el máximo de información arqueológica a partir de ella» Luisa Vetter, Rafael Vega-Centeno, Paula Olivera, Susana Petrick, Editores (2011:09). En II Congreso de Arqueometría,

En las investigaciones sobre Arqueología Amazónica, el uso de la arqueometría está logrando gran importancia para los análisis; la razón principal es que el ecosistema amazónico, por sus condiciones climáticas, no ha permitido la conservación de los artefactos de origen orgánico, los cuales se han descompuesto formando suelos antropogénicos, es decir diferentes a los suelos naturales y que son conocidos por los arqueólogos como «Terras Pretas» o tierras negras, las cuales hoy en día de acuerdo al análisis arqueométrico de sus componentes, están reportando datos e información valiosa sobre las distintas actividades, $y$ también es un indicador sobre el tamańo de la población de las sociedades del pasado amazónico.

La importancia de esta investigación interdisciplinaria entre arqueología y arqueometría es comprobar varias hipótesis sobre el proceso de producción de la cerámica y la dinámica de interacción de los grupos sociales de la Amazonía peruana.

La investigación analítica-arqueométrica de artefactos antiguos como la cerámica arqueológica, nos ha permitido identificar los componentes químicos y mineralógicos que intervienen como materia prima en la elaboración de la cerámica, las cuales además nos permiten acercarnos a las fuentes de origen de las canteras como el inicio de la cadena productiva y la posible existencia de talleres en la elaboración de la cerámica; siendo también de nuestro interés, comprobar analíticamente que el uso del temperante llamado «apacharana» o también "cauchi», el cual, en el caso de la cerámica amazónica tendría un alto contenido de silicatos. En este estudio trabajamos con cinco (5) muestras de sitios arqueológicos diferentes, los que en base a los resultados del análisis mineralógico por Difracción de rayos $\mathrm{x}(\mathrm{DX})$ y análisis por Microscopia Electrónica de Barrido (MEB), es corroborar y complementar estos resultados con los análisis arqueológicos (tipología, estilo y cronología), para poder inferir aspectos sociales sobre la dinámica de desarrollo cultural en la Amazonía peruana.

\section{Metodología}

Esta investigación arqueológica es interdisciplinaria, se usa la arqueometría como método analítico de las ciencias físicas y el análisis tecnológico, tipológico y estilístico de los métodos convencionales de la Arqueología.

El procedimiento a través de las ciencias Físicas es el método de la arqueometria, utilizando el análisis mineralógico por difracción de rayos $\mathrm{X}$ y el análisis por microscopía electrónica de barrido, fueron realizados por el Laboratorio BIZALab del Perú.

Se utilizaron cinco (5) muestras de cerámica de diferentes sitios, para hacer un estudio comparativo con los análisis convencionales de la Arqueología.

El procedimiento a nivel arqueológico, se inició con el registro y la selección de las cinco muestras de cerámica de sitios arqueológicos, luego se procedió con los análisis tecnológicos de las pastas, finalmente se aplicó el método tipológico y estilístico, así de esta manera para conocer el proceso de elaboración de la cerámica, su cronología relativa y su posible filiación cultural. 


\section{Los análisis, hipótesis y discusiones}

Para este trabajo de análisis físico se utilizaron cinco (5) muestras de fragmentos de cerámica, de diferentes sitios arqueológicos que proceden de la Amazonía peruana (Mapa 1). En base a la arqueometría, estas muestras fueron sometidas al análisis por difracción de rayos X y una de las muestras del sitio El Zapotal, fue sometida al análisis por microscopia electrónica de barrido, con la finalidad de conocer los componentes químicos y mineralógicos de los pigmentos utilizados en el engobe.

Teniendo como base los componentes mineralógicos predominantes de las 5 muestras de cerámica arqueológica (Tabla A) y para el caso del sitio El Zapotal, los resultados del análisis mineralógico y microscopia electrónica de barrido (Tabla 1), Figura 1 color del pigmento y fotomicrografías 2, 3, 4, 5, 6, 7 y 8 (ver en anexos). Asimismo, la difracción de rayos $\mathrm{X}$ y los Difractogramas de las Figuras 1. El Zapotal parte externa, 2. El Zapotal parte interna, 3. Chambira, 4. Bagua-Montegrande, 5. Balsapuetro, 6. Pucharini y 7. El Zapotal pasta gruesa (también en anexos). Nuestro interés es conocer:

¿Cuál es la composición química y mineralógica de las 5 muestras de cerámica, y del engobe de la muestra de El Zapotal, asimismo, cuál es el proceso de elaboración o selección de la materia prima que fue usada como colorante?

¿Qué diferencias o semejanzas existen en los distintos materiales en la recolección de la materia prima, para la elaboración de la cerámica?, y con esta información poder agrupar estas muestras a una o varias tradiciones o talleres.

Otro interés deriva del análisis de las pastas de las cerámicas de la Amazonía peruana con métodos convencionales de la arqueología, en base a estos análisis, encontramos casi siempre, el uso de elementos orgánicos como temperantes o desgrasantes en la cerámica. Se trata de la corteza de un árbol llamado "Apacharana», el cual es carbonizado, luego triturado o molido para ser agregado a la arcilla; siendo este un componente orgánico no mineral usado como temperante, a diferencia de los temperantes comunes que son de arena, piedra o cuarzo, los cuales le dan gran resistencia para ser sometidos a la dilatación en momentos de la cocción de la vasija. Contrariamente se supone que los elementos orgánicos en la pasta de la cerámica no tienen las mismas propiedades, que más bien se desintegran y desaparecen en los momentos de la cocción; sin embargo conocemos que los nativos de la Amazonía lo usan, porque según dicen los arqueólogos amazónicos como Meggers (1981) y Lathrap (1970), que esos elementos orgánicos o sea la «apacharana» y la esponja de agua o cauchi en el momento de la cocción en el horno se comportan como un mineral, debido a que contiene en su estructura un alto porcentaje de silicatos. Por lo tanto, nuestro interés es averiguar en base al análisis químico por microscopia electrónica de barrido y difracción de rayos $\mathrm{X}$, si lo que se refiere o dice es científicamente comprobado.

La arqueometría realizada en el laboratorio BIZAlab del Perú, en base al análisis por difracción de rayos $\mathrm{X}$ y el análisis por microscopia electrónica de barrido de una de las muestras, concluyó con los resultados de la Tabla $\mathrm{A}$, donde se indica los componentes mineralógicos mayoritarios de las 5 muestras de los fragmentos de cerámica y los resultados anteriormente citados como anexos.

Para responder y discutir la pregunta, en referencia al engobe, sobre la cual se realizó el análisis mineralógico por difracción de rayos $\mathrm{X}$ y el análisis por microscopia de barrido de la parte externa del fragmento de cerámica (ver Anexos- (Tabla 1), además las Figuras 2, 3, 4, 5 y 6. Todas en referencia a

Tabla A. Composición minerológica mayoritaria de las muestras de artefactos arqueológicos

\begin{tabular}{|l|c|c|c|c|c|}
\hline \multicolumn{1}{|c|}{ Análisis por DRX (\%) } & Plagiociasa & Cuarzo & $\begin{array}{c}\text { Mineral } \\
\text { laminar* }\end{array}$ & Feldespato & Mca \\
\hline Muestra Chambira / Nueva esperanza & 49 & 44 & 3 & $\left(^{*}\right)$ & $\left(^{*}\right)$ \\
\hline Muestra cerámica de Bagua - Amazonas & 14 & 65 & $\left(^{*}\right)$ & 5 & 7 \\
\hline Muestra cerámica Balsapuerto con incisiones - Loreto & $(*)$ & 84 & 13 & $\left(^{*}\right)$ & $\left(^{*}\right)$ \\
\hline Muestra cerámica de Pucharina - Junín & 22 & 52 & 2 & 10 & 10 \\
\hline Muestra cerámica del Zapotal pasta gruesa - Ucayali & 19 & 45 & 3 & 8 & 22 \\
\hline
\end{tabular}

* No se reporta en el análisis 
la muestra de cerámica de El Zapotal, podemos ver que la composición química de los elementos de la superficie externa de la cerámica, o sea el engobe, es consistente con el análisis mineralógico de la difracción de rayo X. Esto quiere decir que los dos tipos de análisis arqueométrico arrojan los mismos elementos químicos y mineralógicos, lo que significa que se trata de la misma arcilla que contiene esmaltita, ortoclasa y plagioclasas, observándose, además, óxido de hierro, que corresponde a hemetita y titanio que corresponde a anatasa.

Entonces debemos entender que en términos arqueológicos, en el proceso de producción de la cerámica, se puede decir que se está usando las mismas canteras para elaborar la cerámica (arcilla y temperantes), incluyendo el engobe de la superficie pintada. Otro aspecto es que, en el análisis de la pasta de la cerámica, la microscopia electrónica de barrido concluye que la composición química corresponde principalmente a Aluminio-silicatos y cuarzo, con una menor proporción de esméctica, en comparación con el análisis de la pasta externa de la cerámica o sea el engobe, es también consistente con los resultados del análisis de difracción de rayos $\mathrm{X}$, que identifica cuarzo, plagioclasas y feldespato en orden de abundancia.

Entonces, arqueológicamente podemos concluir que en la elaboración del engobe que es usado para la superficie de la cerámica, se está seleccionando en mayor proporción los elementos ortoclasa y plagioclasas y en menor proporción la esméctica. Significa que la selección del engobe, posiblemente se hace por decantación de la arcilla, extrayendo la caspa o película superficial más fina para ser usada como engobe.

En general, los alfareros de El Zapotal están seleccionando los materiales que serán usados en la elaboración de las vasijas, tanto en lo referente a la misma arcilla, los temperantes y el engobe, siendo las canteras de extracción ubicadas en la zona geográfica donde están los sitios.

En referencia al color del engobe, el análisis por microscopia electrónica de barrido reporta característica de pigmentos de color Ocre rojo luz (ver en el Anexo Figura 1).

En base a los resultados expuestos en la Tabla A, podemos afirmar y discutir lo siguiente:

1ero. Los componentes mineralógicos de las pastas de las 5 muestras utilizadas en la elaboración de la cerámica son diferentes. Creemos que ello se debe a factores geográficos y de temporalidad cultural, pues a nivel geográfico, los sitios arqueológicos están separados por grandes distancias dentro del territorio de la Amazonia peruana (Mapa 1). Y a nivel de temporalidad cultural, las muestras son de distintas épocas o periodos culturales; por lo tanto, estas sociedades están usando distintas canteras y tendrían distintos talleres de manufactura, ubicados en sus lugares de origen o territorios.

2do. La muestra de la Cuenca del río Chambira, afluente del río Marañón, se diferencia de todas las muestras, o sea es única, por su alto contenido de Plagioclasas (Andesina) con un 49\%, siendo el Cuarzo el $44 \%$ y el mineral laminar con un 3\%. Estos resultados son sumamente importantes y merecen mayor investigación, por el momento está en espera por razones de pandemia, pero es necesario continuar la investigación.

3ro. La cerámica de Montegrande, estilo Bagua, ubicada en la provincia de Jaén, cuenca del Marañón y la cerámica de Balsapuerto, ubicada en el río Cachiyacu-Paranapura, afluente del río Huallaga (Mapa 1), según Tabla $\mathrm{A}$, tienen altos contenidos de Cuarzo: con $65 \%$ en la muestra de Montegrande y $84 \%$ en la muestra de Balsapuerto. Asimismo, Balsapuerto se diferencia porque no comparte con ninguna de las muestras los elementos de Plagioclasas, en cambio tiene $13 \%$ de mineral laminar; Montegrande además tiene $5 \%$ de feldespato y $7 \%$ de mica. Aquí las diferencias entre ambas se deben a factores cronológicos, pues Montegrande es una cerámica bastante temprana del periodo Formativo, 1200 a 800 a. C., mientras que Balsapuerto es bastante tardía, $1000 \mathrm{~d}$. C.

4to. La cerámica de Pucharini, ubicada en la cuenca del río Perené, es muy particular, tiene 52\% de cuarzo, 22\% de Plagioclasas, 2\% de material laminar, $10 \%$ de feldespato y $10 \%$ de mica. La cerámica de El Zapotal (con temperante de cerámica molida), ubicada en la cuenca del río Samiria, confluencia del rio Marañón y Ucayali, y la cerámica de Pucharini, supuestamente contemporáneas, comparten los mismos elementos mineralógicos, pero en proporciones o porcentajes un poco diferentes. Zapotal tiene 19\% de Plagioclasas y Pucharini 22\%, Zapotal tiene 45\% de cuarzo y Pucharini tiene 52\%; Zapotal tiene 3\% de material laminar, Pucharini 2\%; Zapotal tiene 8\% 


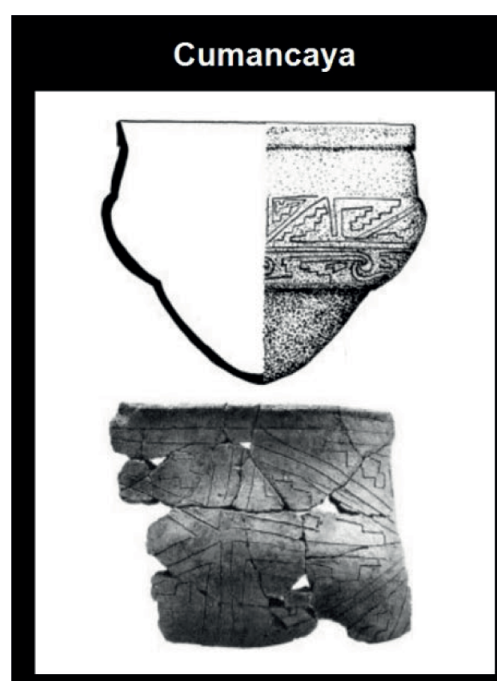

(Lathrap 1970)

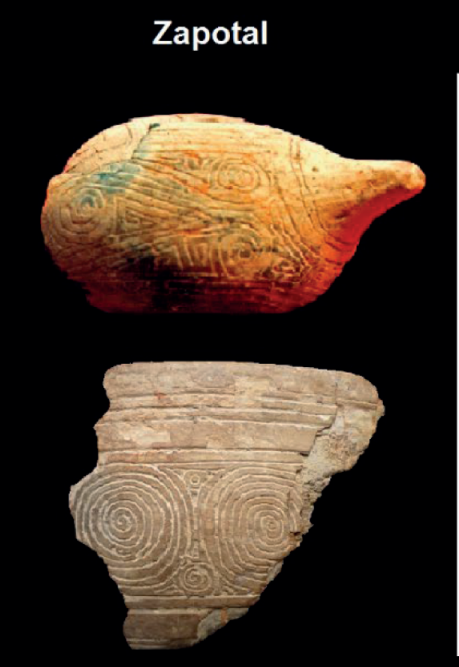

(Fotografía de Daniel Morales)

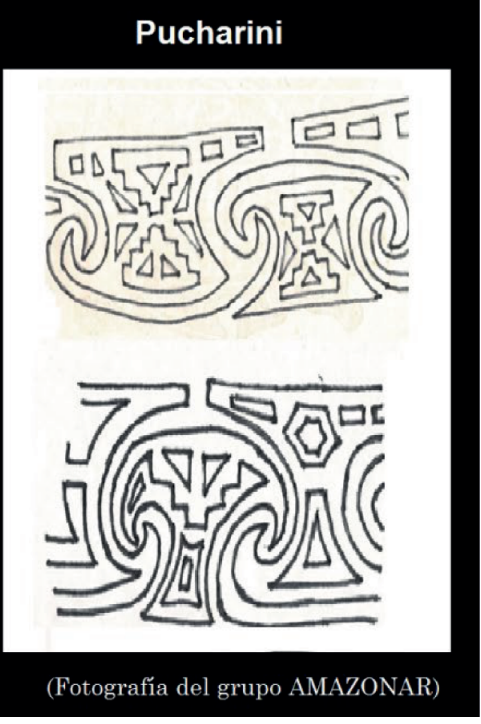

Lámina 1. Diseños incisos de la cerámica Cumancaya, El Zapotal y Pucharini comparten en sus estilos figuras de triángulos, escalones y espirales. de feldespato, Pucharini 10\% y finalmente Zapotal tiene $22 \%$ de mica y Pucharini $10 \%$.

Es probable que estas similitudes entre Zapotal y Pucharini, se deba a factores temporales y culturales; pues estilísticamente ambas comparten algunos rasgos con la cerámica de estilo Cumancaya del Ucayali, (Lámina 1, dibujos de los diseños de la cerámica El Zapotal, Pucharini y Cumancaya ), que cronológicamente se ubican entre los años 800 a 1500 d. C.; además los tres sitios están en la misma cuenca del Ucayali, aunque Pucharini está en un tributario, llamado río Perené y El Zapotal se ubica en la cuenca baja del Marañón-Ucayali, bastante distante del río Perené, como se observa en el mapa.

Sin embargo, creo que las semejanzas entre los elementos mineralógicos de la pasta del El Zapotal y Pucharini se debe a que ancestralmente compartían la misma tecnología en el uso de materias primas, a pesar de que están muy alejadas, lo que constituye una verdadera tradición ancestral; además un ejemplo interesante es también el contenido en ambas cerámicas de los elementos de Plagioclasas, que a la vez contienen andesina, oligoclasas y albita, las que contienen alto contenido de aluminosilicatos, el cual a nuestro entender seria el resultado de que ambas están usando como materia prima la "Apacharana", carbonizada y triturada como temperante; y que las diferencias en los porcentajes de los elementos mineralógicos y algunos rasgos estilísticos se debería a la separación de Pucharini en un momento histórico, alejándose de El Zapotal y el Ucayali Central.
Estos aspectos resultan muy interesantes, porque como mencionamos, culturalmente creemos que ambos comparten algunos rasgos estilísticos con la cerámica del estilo Cumancaya del Ucayali Central estudiada por D. Lathrap, (1970) (ver lámina 1, estilos de los tres).

Sin embargo, un rasgo estilístico de Cumancaya y El Zapotal es la cerámica corrugada (Lámina 2: cerámica corrugada del Ucayali Central y El Zapotal), no es compartido con el sitio de Pucharini. Lathrap (1970), plantea que este rasgo de la tradición Cumancaya, es decir la cerámica Corrugada es uno de los componentes que se incorporó a la tradición Cumancaya, probablemente después de los años 1000 d. C.; lo cual nos lleva a suponer que la separación entre los dos grupos culturales (Pucharini y Cumancaya), debió ocurrir antes de los años 1000 d. C., es decir el tiempo que demoró que Pucharini llegue a la cuenca del río Perené desde su posible antiguo asentamiento en el Ucayali.

Estas deducciones se hacen interesantes, porque sabemos que, históricamente en la Cuenca del Ucayali, según D. Lathrap (1970), hubo una dinámica de desplazamientos poblacionales, provocados por el acceso a los mejores y más abundantes recursos de las zonas rivereñas y otros factores sociales como es: el aumento poblacional, las guerras o conflictos entre los grupos desplazando hacia las cuencas altas o tributarios del río Ucayali; entonces suponemos que los Pucharini fueron desplazados a las cabeceras de los ríos tributarios del Ucayali, acontecimiento que 


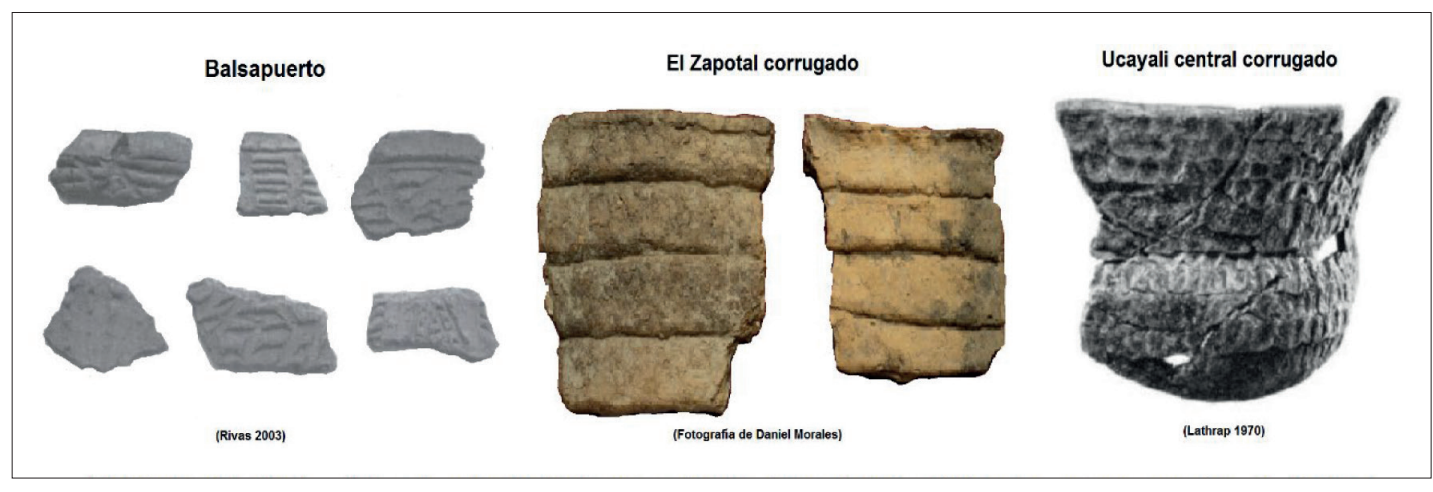

Lámina 2.

Dibujo de

la cerámica

corrugada

del estilo

Cumancaya

del Ucayali

central y El

Zapotal. Estos

rasgos no son

compartidos

con Pucharini.

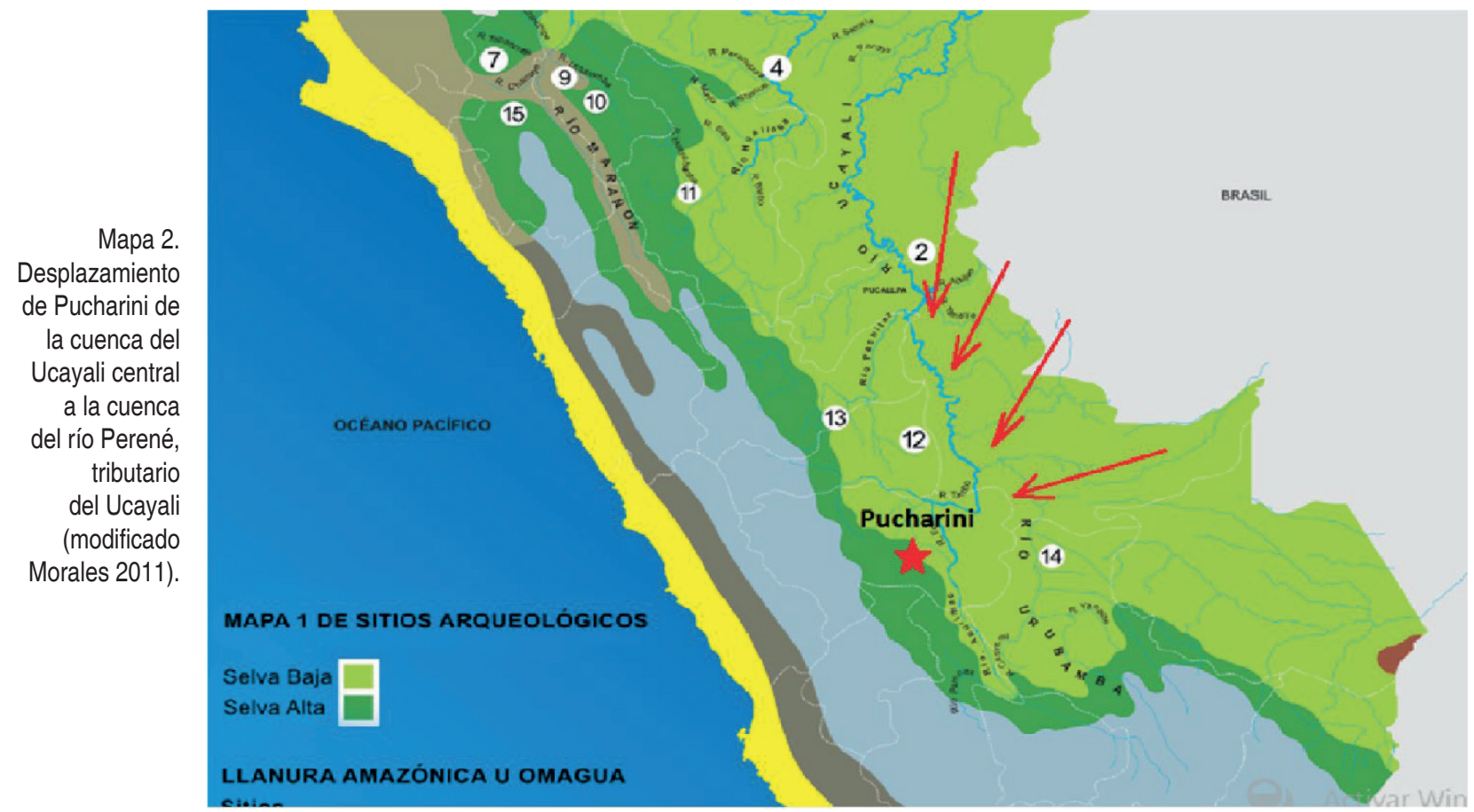

habría ocurrido antes de los 1000 d. C., ya que posterior a esta fecha el estilo Cumancaya del Ucayali incorpora la convivencia de otro grupo social que traía los componentes de la cerámica corrugada (Mapa de desplazamiento de Pucharini)

Sabemos también, según D. Lathrap que los grupos que tenían el estilo de cerámica corrugada, provenían del sur Amazónico (Bolivia); además se conoce que esta cerámica corrugada está asociada con poblaciones de lengua Tupi-Guaraní, quienes a partir de los ańos 500 d. C., empezaron a invadir la cuenca amazonia, viniendo desde las costas atlánticas y penetrando por la boca del Amazonas hasta el corazón de la Amazonía central y todos sus tributarios.

Las poblaciones Tupi-Guaraní, en la Amazonía central se unieron a las poblaciones sociales más desa- rrolladas que tenían el estilo de cerámica policroma, y a partir de los 1000 d. C. los dos estilos estaban fusionados y son encontrados en las excavaciones de los arqueólogos y son mencionados como el estilo Policromo Corrugado de la Amazonía (Meggers, 1981)

Pucharini, no comparte estos acontecimientos sociales, porque ya anteriormente había sido desplazado a un tributario del Ucayali, es decir a la cuenca del río Perené, donde los Tupi-Guaraní al parecer no llegaron. Este hecho social, significaría que los Pucharini son miembros de otro grupo social distinto al Tupí-guaraní, sin embargo, queda por investigar a qué grupo social lingüístico pertenecen los Pucharini.

Aquí la interrogante se plantea, porque en la cuenca del río Ucayali, antes y en el presente están 
poblados por los grupos de lengua Pano, cuyos representantes actuales son los Shipibo-Conibo, quienes serían los que probablemente desplazaron a los Pucharini de la cuenca del Ucayali; mientras que el territorio geográfico del río Perené donde está el sitio de Pucharini, pertenece a los grupos lingüísticos Arawak, dentro de los cuales están los Yanesha, Campas, Piros y Machiguengas; entonces es posible que los Pucharini, pertenezcan al Grupo lingüístico Arawak.

5to. Ahora, ¿Qué pasa con la cerámica de Balsapuerto, la cual es contemporánea estilísticamente con El Zapotal y también con Pucharini?

Balsapueto tiene un alto contenido de cuarzo $84 \%$, muy superior a El Zapotal y Pucharini que tienen $45 \%$ y $52 \%$ respectivamente (Tabla A), Pucharini tiene $22 \%$ de Plagioclasas y El Zapotal tiene 19\%; en cambio Balsapuerto no tiene Plagioclasas, ni feldespato y tampoco mica, que El Zapotal y Pucharini si tienen, esto no solo implicaría una mayor separación geográfica y cultural de Balsapuerto; es también probable que Balsapuerto perteneció a una tradición cultural más andina que Amazónica, por su alto contenido de cuarzo y por la falta de Plagioclasas (es decir no usa apacharana). Ahora a nivel cultural El Zapotal y Balsapuerto, geográficamente no son tan alejadas, comparten algunos rasgos estilísticos con la cerámica corrugada, el impreso con cordel y el rojo entre incisiones (Lámina 3), y cronológicamente son casi contemporáneas, es decir se ubican entre los años 1000 a $1450 \mathrm{~d}$. C.

Pucharini no comparte la cerámica corrugada con Balsapuerto y El Zapotal, por las razones ya explicadas; a la vez Pucharini, El Zapotal y Balsapuerto comparten algunos rasgos del estilo Cumancaya. Es decir existen algunos vínculos ancestrales en los tres grupos, son casi contemporáneos pero están alejados unos de otros, esto probablemente se explique por la dinámica de desplazamientos planteada por Lathrap (1970), a ello también se debe las marcadas diferencias, el cual no solo se debe a las distancias que los separa, sino también que nos muestra la complejidad de las relaciones y acontecimientos sociales ocurridos en el pasado cultural de la Amazonía peruana, donde los rasgos estilísticos de la cerámica de distintos grupos sociales esta interactuando y conviviendo con otros grupos sociales, incluso muy distintos en su estructura lingüística.

Todas estas discusiones e inferencias deben ser producto de la multitud de redes hidrográficas de los ríos mayores y tributarios, los cuales discurren en un territorio de llanura amazónica, cuya facilidad de desplazamiento por río, originan los llamados Horizontes estilísticos y tradiciones culturales com-
Impreso con cordel
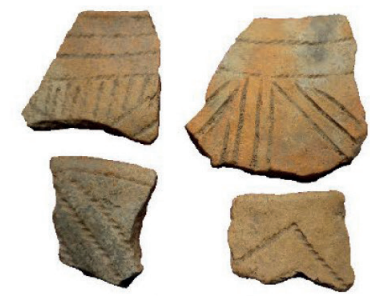

El Zapotal

(Fotografia Daniel Morales)

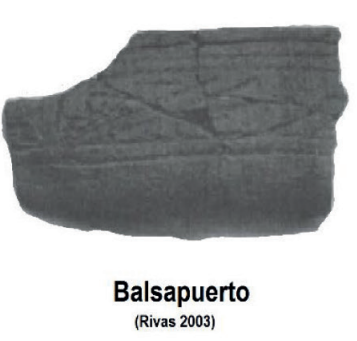

Rojo entre incisiones

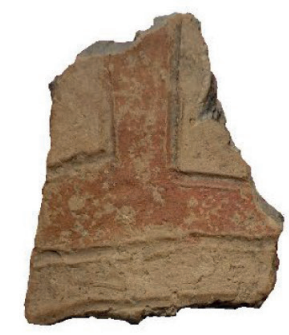

El Zapotal

(Fotografia Daniel Morales)

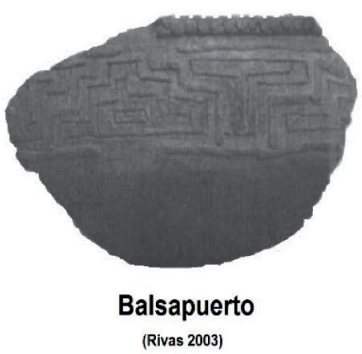

\section{Corrugado}
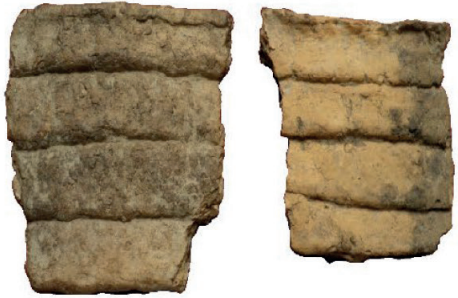

El Zapotal

(Fotografia Daniel Morales)

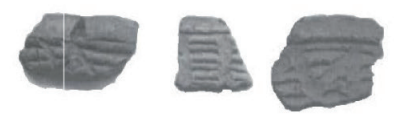

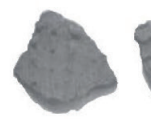
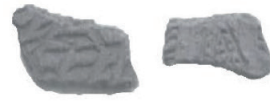

Balsapuerto (Rivas 2003)
Lámina 3.

El Zapotal y

Balsapuerto

comparten

la cerámica

impresa

con cordel,

rojo entre

incisiones y

corrugago.

Mientras que

Pucharini no

comparte

estos estilos

de cerámica. 
partidas entre diferentes grupos sociales. Siendo este, un motivo de gran valor para afirmar que la dinámica cultural en la Amazonía peruana es muy distinta a lo acontecido en el Área Andina.

\section{Conclusiones}

El análisis por microscopia electrónica de barrido del engobe de la superficie de la cerámica El Zapotal, reporta que es característico de pigmentos de color ocre rojo luz (Ver Figura 1 en Anexos), que contiene óxido de hierro y titanio. Los componentes químicos y mineralógicos de la superficie externa (o sea el engobe), y la parte interna de la pasta, arroja una diferencia que es un mayor porcentaje de esmécticas en la parte interna de la pasta, lo que indicaría que el engobe se está seleccionando con mayor proporción de elementos de ortoclasa y plagioclasas y en menor proporción las esmécticas; arqueológicamente esto significa que hay una selección de los materiales que son usados en la elaboración de la cerámica, tanto en lo referente a las arcillas, los temperantes y el engobe.

Los resultados de los componentes mineralógicos según análisis por difracción de rayos $\mathrm{X}$, de cinco muestras de cerámica de la amazonia peruana, con ubicaciones geográficas diferentes y sus relaciones cronológicas y estilísticas, nos permiten conocer diferentes aspectos socio-culturales de las sociedades prehispánicas de la Amazonía.

Considerando que cada taller de producción alfarera representa una tradición tecnológica, que se manifiesta en el uso de las mismas fuentes de materia prima (arcillas, temperantes y manufactura); visto los resultados de los componentes mineralógicos de las cinco muestras de cerámica, las cuales son diferentes, concluimos que las sociedades a las que representan cada una de las muestras, tendrían sus propios talleres de manufactura, ubicados en sus territorios o lugares de origen.

La muestra de Balsapuerto, por su alto contenido de Cuarzo (84\%), y la falta de Plagioclasas entre sus componentes mineralógicos, se vincularía más a las tecnologías andinas, que por lo general usan como temperante abundante cuarzo, mientras que el uso de los componentes de plagioclasas es muy particular para las cerámicas amazónicas.
La existencia de semejanzas entre los componentes mineralógicos de Pucharini y El Zapotal, especialmente de los componentes de Plagioclasas, los cuales tienen un alto contenido de Aluminosilicatos, que a nuestro entender, sería el resultado del uso como temperante de la corteza del árbol llamado "Apacharana», el cual en momentos de la cocción se comporta como un mineral (aluminosiliocatos).

Balsapuetrto, Pucharini, y El Zapotal, además comparten algunos rasgos con el estilo Cumancaya del Ucayali, que cronológicamente esta entre los años 800 a 1500 d. C., que los hace contemporáneos.

La cerámica de Pucharini no comparte con Balsapuerto, El Zapotal y Cumancaya la cerámica corrugada, la cual según Lathrap (1970), se incorpora al estilo Cumancaya después de los años $1000 \mathrm{~d}$. C. y nos estaría indicando que Pucharini se separó de la tradición compartida antes de los $1000 \mathrm{~d}$. C.

El desplazamiento de Pucharini, hacia la cuenca del río Perené, un afluente del Ucayali, nos confirma la dinámica cultural Prehispánica en la Amazonía peruana, planteada por Lathrap(1970), dinámica que se expresa en compartir rasgos estilístico de una misma tradición, entre grupos sociales distantes, diversos y diferentes incluso en su estructura lingüística, sean estos Tupi-Guaraní, Panos o Arawaks.

La dinámica cultural de desplazamiento en las sociedades Amazónicas y el hecho de compartir algunos rasgos estilísticos entre ellos, además de los factores sociales ya explicados, se debe a la multitud de redes hidrográficas de los ríos mayores y sus tributarios, los cuales discurren en un territorio de llanura Amazónica, cuya facilidad de desplazamiento por los ríos, crea tradiciones compartidas entre sociedades incluso diferentes en su estructura lingüística.

\section{Agradecimientos}

Agradecemos al laboratorio BIZAlab por el análisis de microscopia óptica electrónica de barrido de dos muestras y Difracción de Rayos X de cinco muestras de cerámica.

Esta investigación fue llevada a cabo por el Grupo de Investigación Arqueología Amazónica (AMAZONAR), de la Facultad de CC.SS. y FLCH de la UNMSM, en colaboración con el Ministerio de Cultura y la Dirección Desconcentrada de Junín. 
Agradecemos igualmente al arqueólogo J. Sulca, quien hizo el rescate de las urnas funerarias en el sitio de Pucharini en la cuenca del río Perené.

Asimismo, colaboraron con muestras de cerámica de Bagua, el Dr. Quirino Olivera, la arqueóloga Lesly García con muestras de cerámica de Balspuerto y Daniel Morales con las muestras del Chambira y El Zapotal. En el trabajo de gabinete apoyaron el arqueólogo Irvin Navarro y los alumnos de arqueología Ángela Piñeiro, Nathaly Solís y Jairo Mestanza.

\section{Referencias}

Allen, Willam (1968) A ceramic secuence from the Alto Pachitea, Perui:Some implication for the develoment of tropical forest culture in south American. Ph.D. disertation departamento of Anthropology. University of Illinos.Urbana-Champaign.

Shimada, Isumi (2011) Hacia una mejor integración de la Arqueometría y la Arqueología andina: el caso de Pachacamac. II Congreso Latinoamericano de Arqueometría. Editores: Luisa Vetter, Rafael vegaCenteno, Paula Olivera y Susana Petrick. Presentación Pp. 29-56.

Lathrap, Donald (1970). The Upper Amazon. Ancient Peoples and Places Series. Vol. 70, Praeger, New York and Washington.

Lazo, Roxana, Mac Kay, M., Pillaca, M., y Landauro, C. (2011), "Caracterización de elementos presentes en fragmentos de cerámica de dos estilos diferentes: Lima (Lima) y Chaquipampa (Ayacucho) encontrados dentro del complejo Maranga. En II Congreso Latinoamericano de Arqueometría. Editores: Luisa Vetter, Rafael Vega-Centeno, Paula Olivera y Susana Petrick. Pp. 230-262.
Makowski, K., Ghezzi I., Neft, H., Guerrero, D., Jimenez, M., Ore, G., Alvarez Calderon, R. (2011) Restos de producción e intercambio en el Horizonte Tardío: Caracterización con LA-TOF-ICPMS e INAA de arcillas y estilos cerámicos en la costa Central del Perú. En II Congreso Latinoamericano de Arqueometría, Editores: Luisa Vetter, Rafael VegaCenteno, Paula Olivera y Susana Petrick. Pp. 263-276

Meggers, Betty (1981) La reconstrucción de la pre-Historia Amazónica. En Amazonia Peruana del Centro Amazónico de Antropología y Aplicación Práctica (CAAAP).Pp.15-30.

Morales, Daniel (1992) Chambira: Alfareros tempranos de la Amazonía peruana. En Estudios de Arqueología Peruana. Editor: Duccio Bonavia, FOMCIENCIAS. Pp.149-176.

(2019) Investigaciones Arqueológicas en el sitio El Zapotal, Loreto-Perú. Tesis para optar el grado de Maestría en Arqueología en la Pontificia Universidad Católica del Perú.

Olivera, Quirino (2018) Jaén Arqueología y Turismo. Yanapay Andina consultores y Municipalidad Provincial de Jaén. Pps.247.

Rivas, Santiago (2003) Los Asentamientos Prehispánicos de la cuenca del Río Chachiyacu, Amazonia Peruana». Publicación del Instituto Cultural Runa. Pp. 142.

Raymond, S., De Boer, W., y Roe, P. (1975) Cumacaya: a peruvian ceramic tradition. Occasional Papers $\mathrm{N}^{\circ} 2$, Departament of Archeology the University of Calgary. Pps.143.

Shady, Ruth. (1974) La arqueología de la cuenca inferior del Utcubamba. Tesis de Doctorado. UNMSM. 150 pp. Lima.

Vetter, Luisa, Vega-Centeno, Rafael, Olivera, Paula y Petrick, Susana (2011) II Congreso Latinoamericano de Arqueometría, Presentación a la Edición, pp. 9-12. 


\section{Anexos}

\section{Tabla 1}

\section{Análisis por microscopia electrónica de barrido}

La microscopia de barrido reporta que la composición química de los elementos, con base de cálculo sin consideración del oxígeno, característica de pigmentos de coloración ocre rojo luz (Tabla 1). Lo anterior es posible verificarlos con estudios anteriores realizados a pigmentos (ver Anexos).

TABLA 1. Análisis EDS (elementos) en el pigmento o parte externa de Muestra Fragmento Cerámica Sitio arqueológico El Zapatal - Parte Externa

\begin{tabular}{|c|c|c|c|c|c|c|c|c|c|c|}
\hline \multirow{2}{*}{$\begin{array}{c}\text { Análisis EDS } \\
\text { (elementos) }\end{array}$} & \multicolumn{9}{|c|}{ Composición química (\%) } & \multirow[t]{2}{*}{ TOTAL } \\
\hline & $\mathrm{Si}$ & $\mathrm{Ti}$ & $\mathrm{Al}$ & $\mathrm{Fe}$ & $\mathrm{Mg}$ & $\mathrm{Ca}$ & $\mathrm{Na}$ & K & $\mathrm{P}$ & \\
\hline Análisis 2048 & 0.60 & 11.55 & 1.66 & 84.01 & 2.18 & & & & & 100 \\
\hline Análisis 2049 & 32.53 & 1.83 & 13.71 & 40.41 & 5.77 & & & 5.75 & & 100 \\
\hline Análisis 2050 & 62.42 & & 15.02 & 12.29 & 2.24 & 4.12 & 1.76 & 2.15 & & 100 \\
\hline Análisis 2051 & 49.38 & & 28.76 & 10.04 & 3.73 & 2.55 & 2.39 & 3.15 & & 100 \\
\hline Análisis 2052 & 41.11 & & 28.22 & 16.50 & 3.75 & 3.61 & & 5.15 & 1.67 & 100 \\
\hline Análisis 2054 & 12.28 & & 6.24 & 74.72 & 2.37 & 2.58 & & 0.56 & 1.26 & 100 \\
\hline Análisis 2055 & 56.01 & & 24.60 & 7.19 & & 1.66 & 8.35 & 2.19 & & 100 \\
\hline Análisis 2056 & 52.02 & & 21.49 & 17.53 & 1.89 & 2.03 & & 5.04 & & 100 \\
\hline Análisis 2057 & 54.96 & & 5.51 & 38.66 & & & & 0.88 & & 100 \\
\hline Análisis 2058 & 56.79 & & 23.85 & & & 1.23 & 18.13 & & & 100 \\
\hline Análisis 2060 & 31.97 & & 17.68 & 43.20 & 2.70 & 1.74 & & 1.35 & 1.37 & 100 \\
\hline Análisis 2061 & 44.95 & 1.33 & 23.15 & 19.85 & 2.47 & 3.21 & 1.21 & 2.93 & 0.90 & 100 \\
\hline Análisis 2062 & 46.81 & 1.15 & 23.93 & 16.83 & 2.28 & 3.0 & 1.79 & 4.20 & & 100 \\
\hline
\end{tabular}

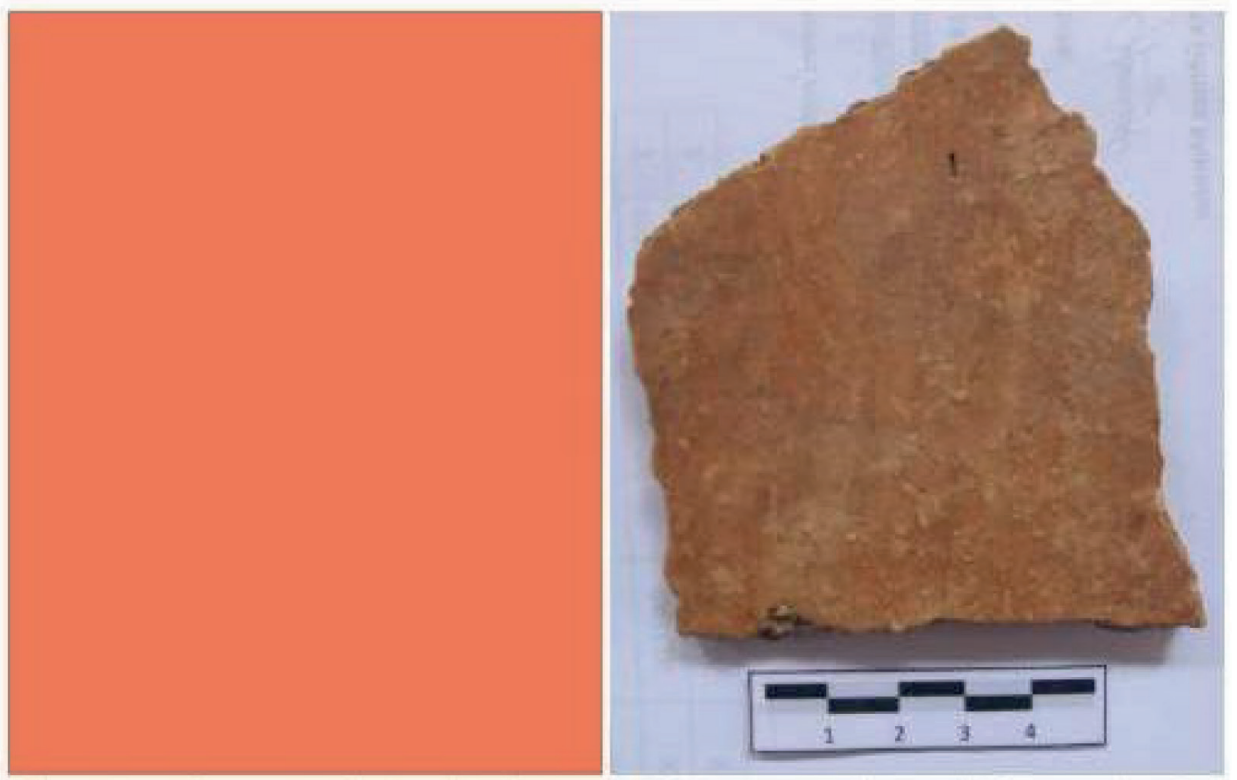

Figura 1. Color característico del pigmento de fragmento de cerámica, tendiendo a color ocre rojo luz. La composición química es consistente con los colores del pigmento en el fragmento de cerámica (Tabla 1 y Anexos). 


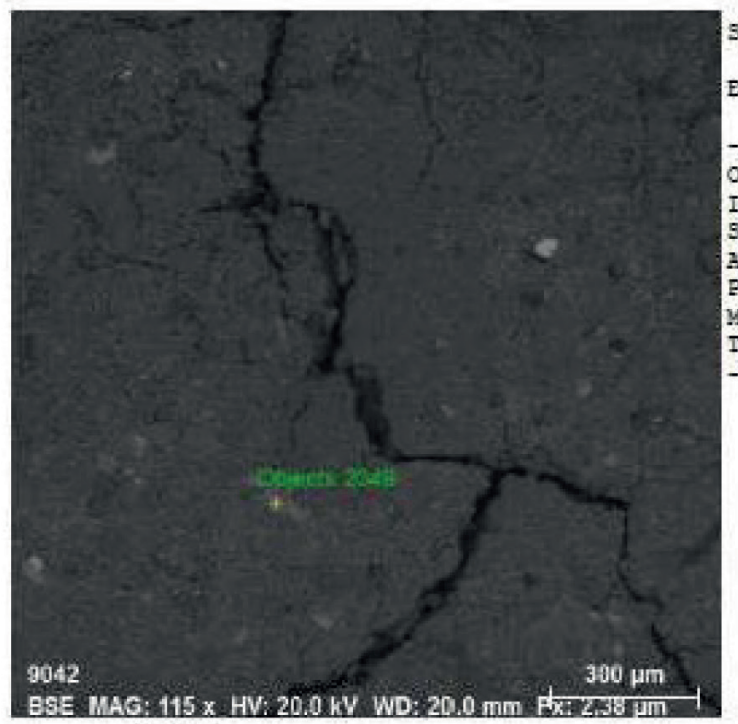

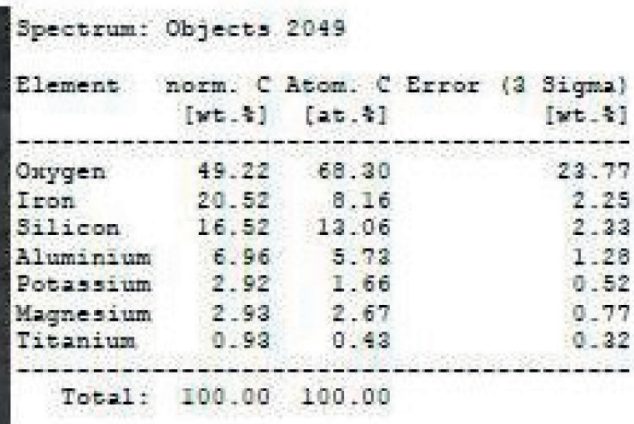

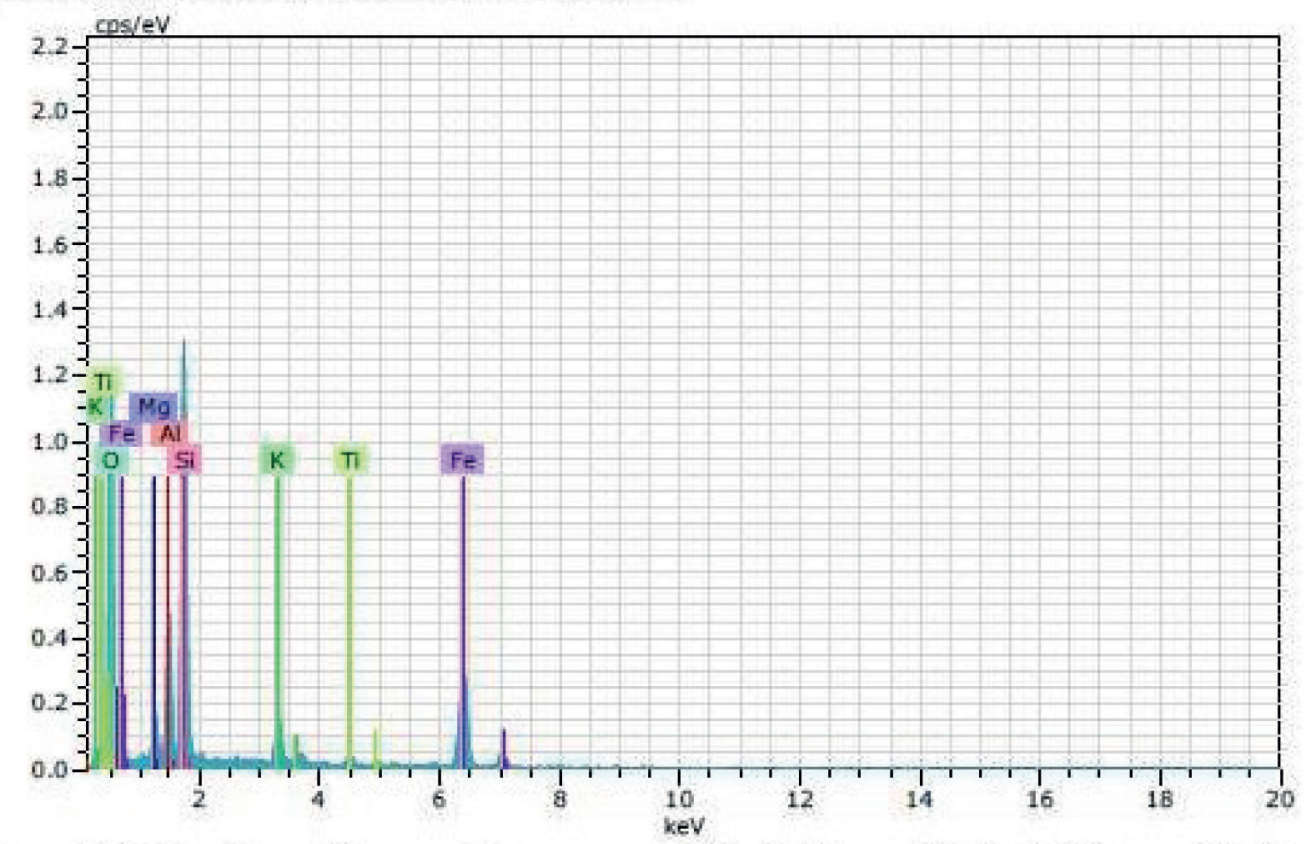

Figura 2. Fotomicrografía, espectro y composiciónde fase oxidada de hierro y titanio, principalmente. 


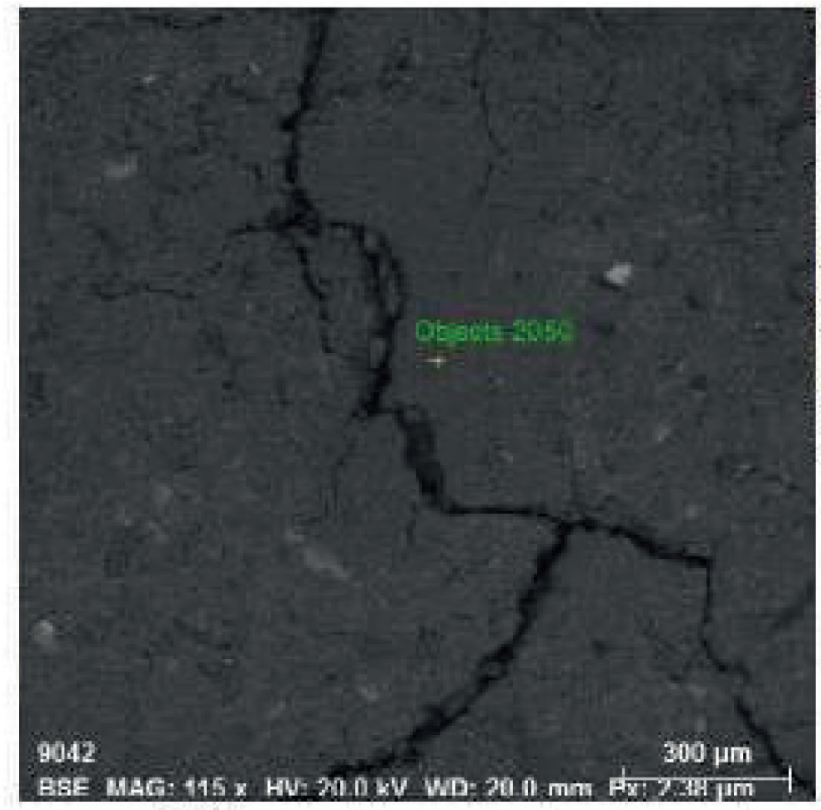

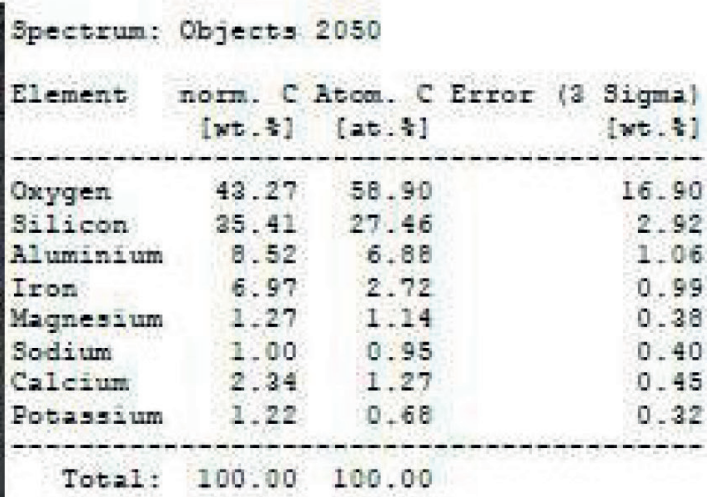

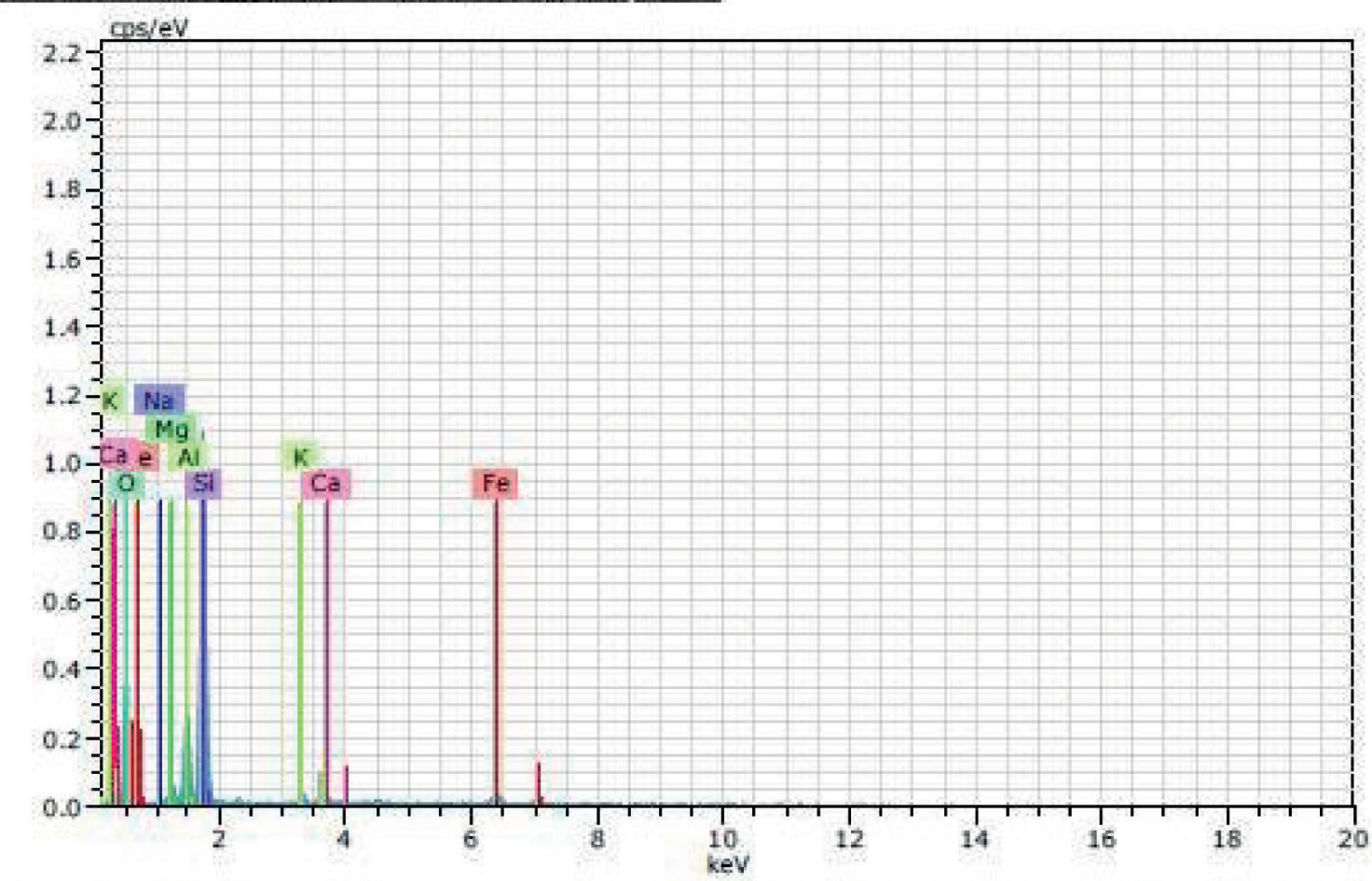

Figura 3. Fotomicrografía, espectro y composiciónde fase oxidada de hierro y titanio, principalmente. 


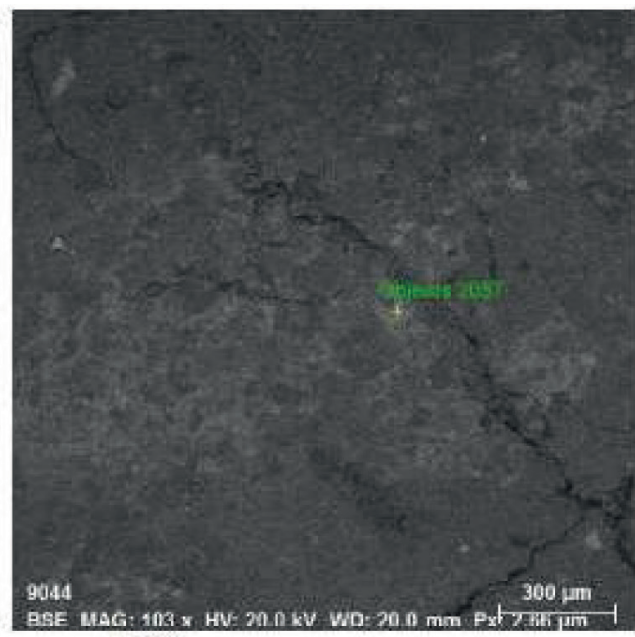

Bpectrum: Objects 2057

Element norm. C Atom. C Error (3 Sigma)

[wt.s] [at.s] [wt.8]

twe.

Oxygen $\quad 46.61 \quad 67.27 \quad 23.32$

$\begin{array}{llll}\text { Bilieon } & 28.25 & 22.27 & 3.46\end{array}$

$\begin{array}{llll}\text { Iron } & 19.87 & 7.88 & 2.29\end{array}$

Aluminium $2.93 \quad 2.32 \quad 0.69$

Potassium $0.45 \quad 0.25 \quad 0.24$

Potassium

Total : $100.00 \quad 100.00$

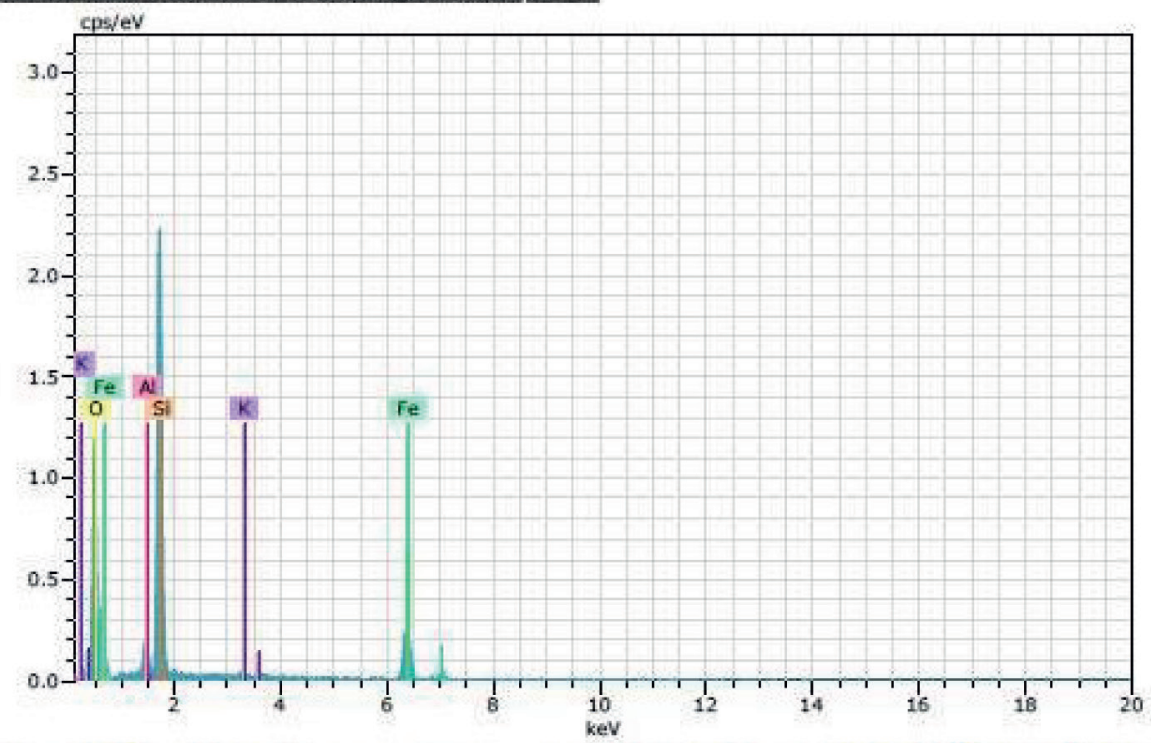

Figura 4. Fotomicrografía, espectro y composiciónde fase oxidada de hierro y titanio, principalmente. 


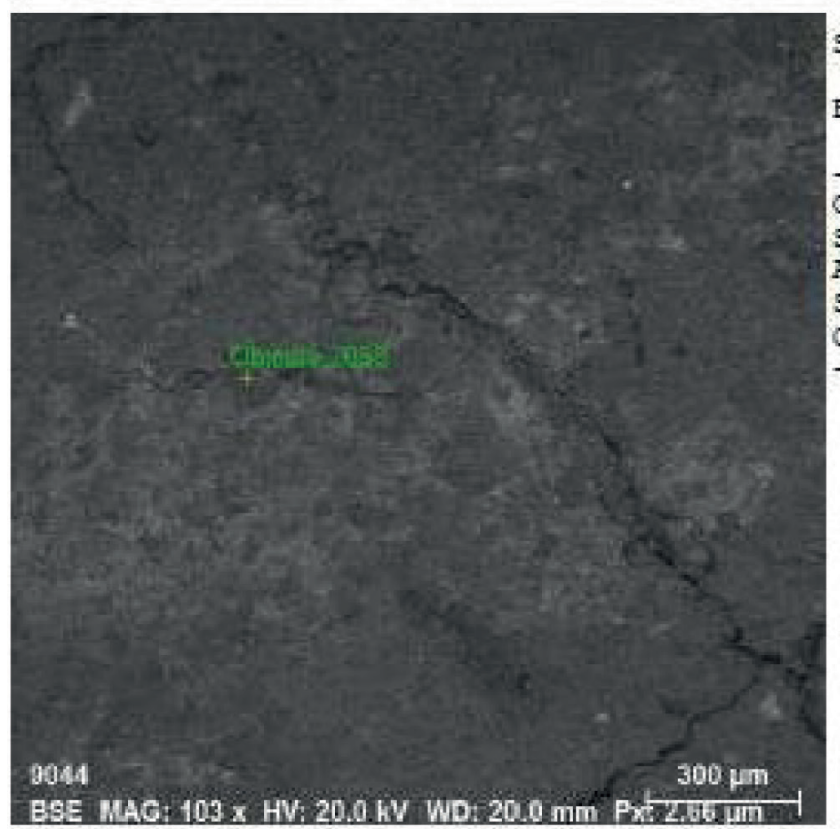

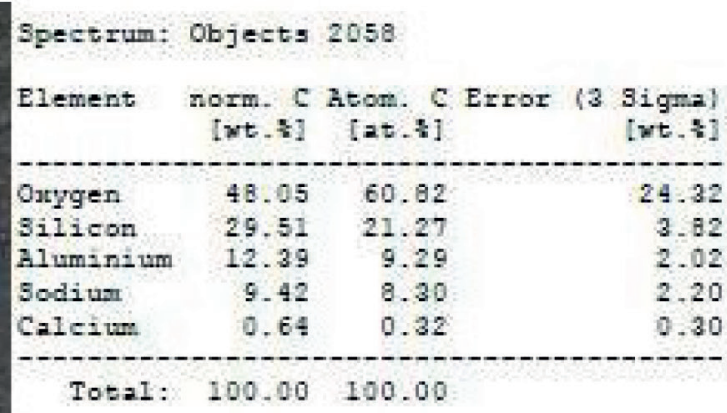

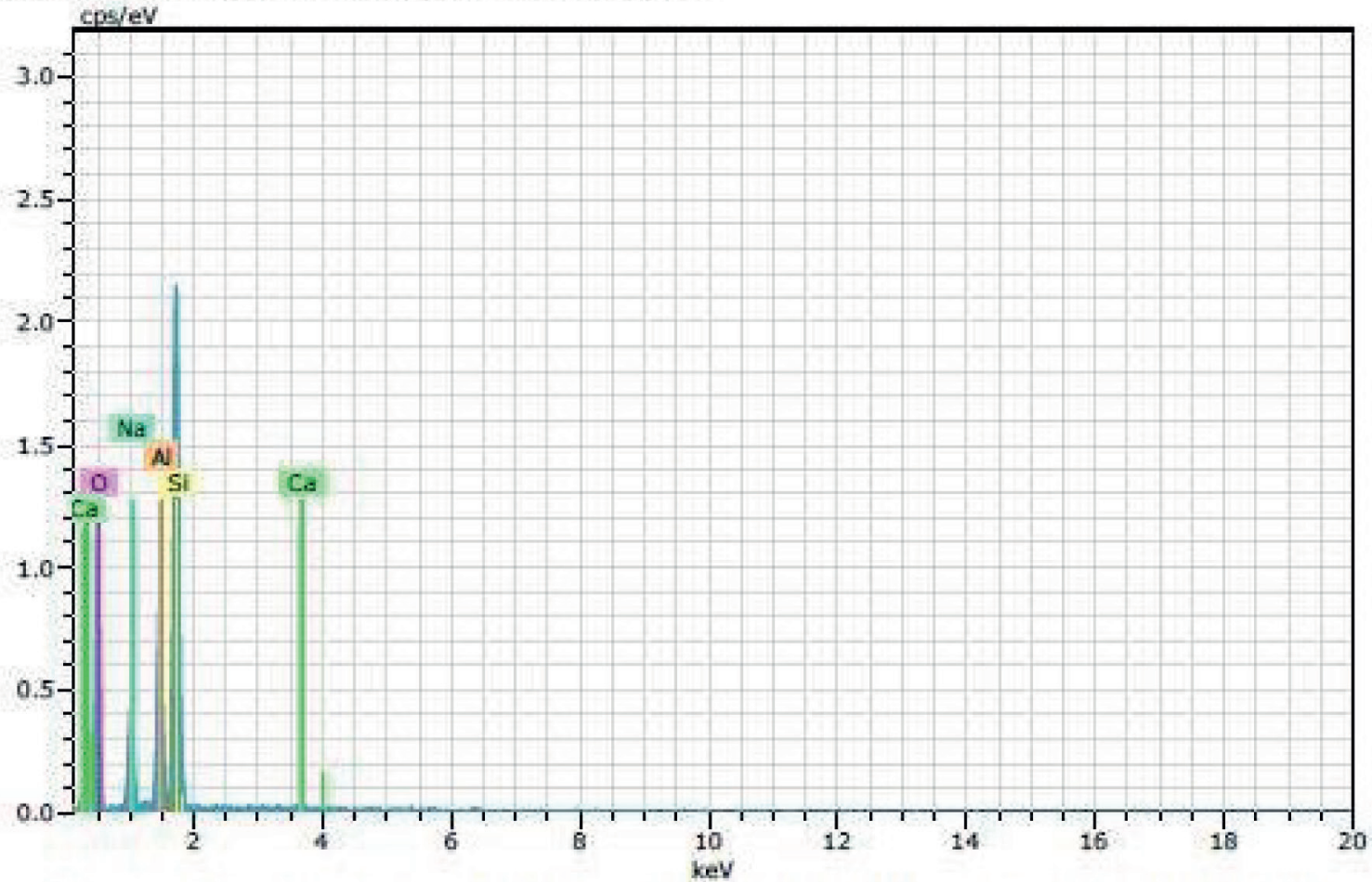

Figura 5. Fotomicrografía, espectro y composiciónde fase oxidada de hierro y titanio, principalmente. 


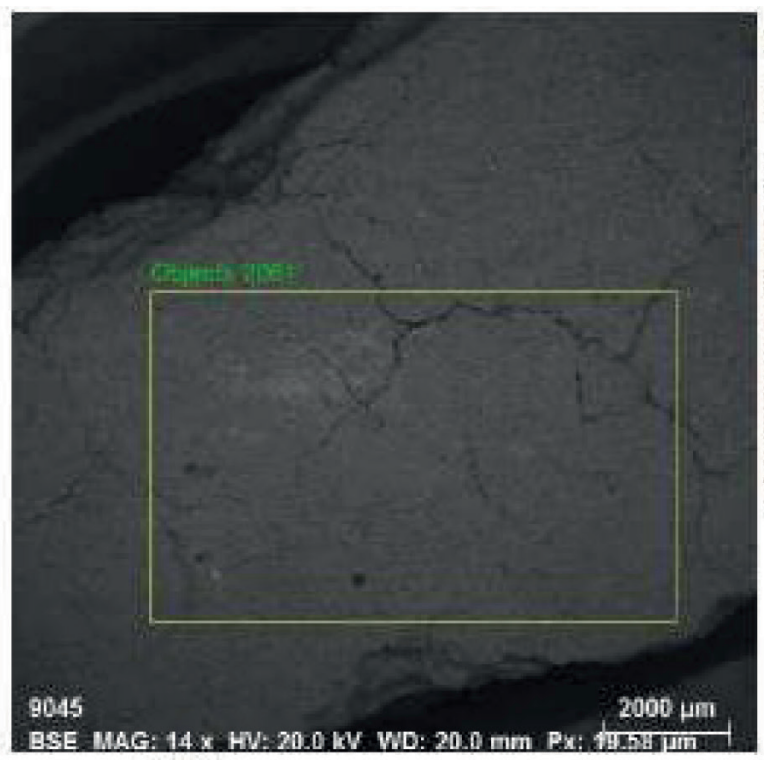

\begin{tabular}{|c|c|c|c|c|}
\hline Element & $\begin{array}{l}\text { norm. } c \\
\text { [wt . s] }\end{array}$ & $\begin{array}{l}\text { Atom. C } \\
\text { [at.s] }\end{array}$ & Error 13 & $\begin{array}{l}\text { Bigna) } \\
\text { [urt - } 7 \text { ] }\end{array}$ \\
\hline Oxygen & 49.78 & 66.08 & & 23.31 \\
\hline Silicon & 22.50 & 17.07 & & 2.65 \\
\hline Iron & 9.97 & 3.79 & & 1.36 \\
\hline Aluminium & 11.63 & 9.16 & & $1.6 I$ \\
\hline Calcium & 1.61 & 0.85 & & 0.40 \\
\hline Potassium & 1. 47 & 0.80 & & 0.37 \\
\hline Magnesium & 1.24 & 1.09 & & 0.43 \\
\hline Phosphorus & 0.45 & 0.31 & & 0.24 \\
\hline $\begin{array}{l}\text { Titanium } \\
\text { Sodium. }\end{array}$ & $\begin{array}{l}0.67 \\
0.61\end{array}$ & $\begin{array}{l}0.30 \\
0.56\end{array}$ & & $\begin{array}{l}0.29 \\
0.36\end{array}$ \\
\hline
\end{tabular}

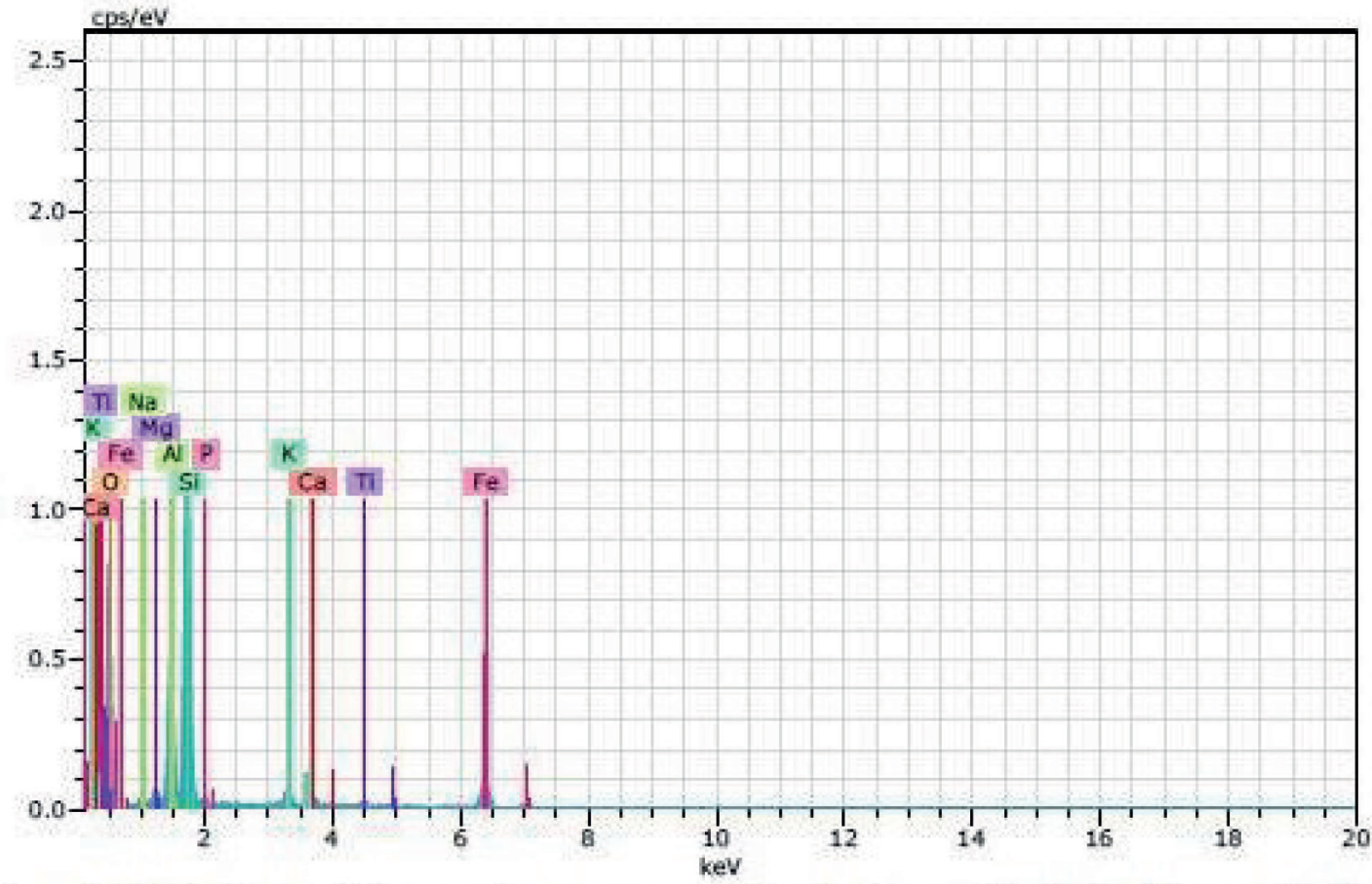

Figura 6. Fotomicrografía, espectro y composiciónde fase oxidada de hierro y titanio, principalmente. 


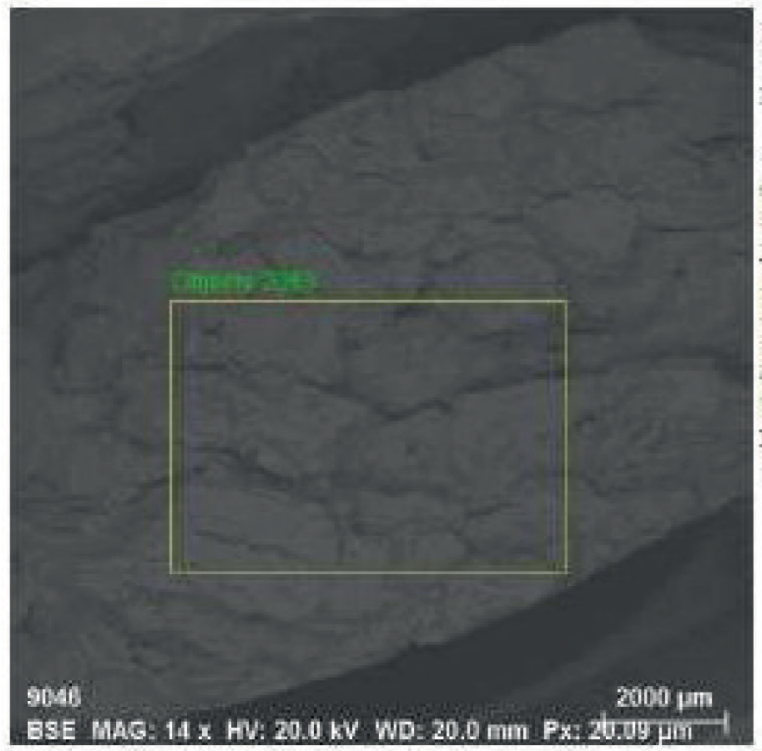

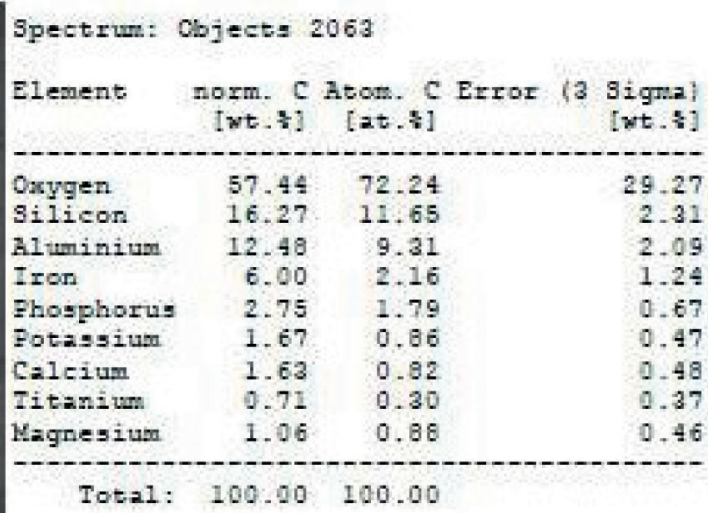

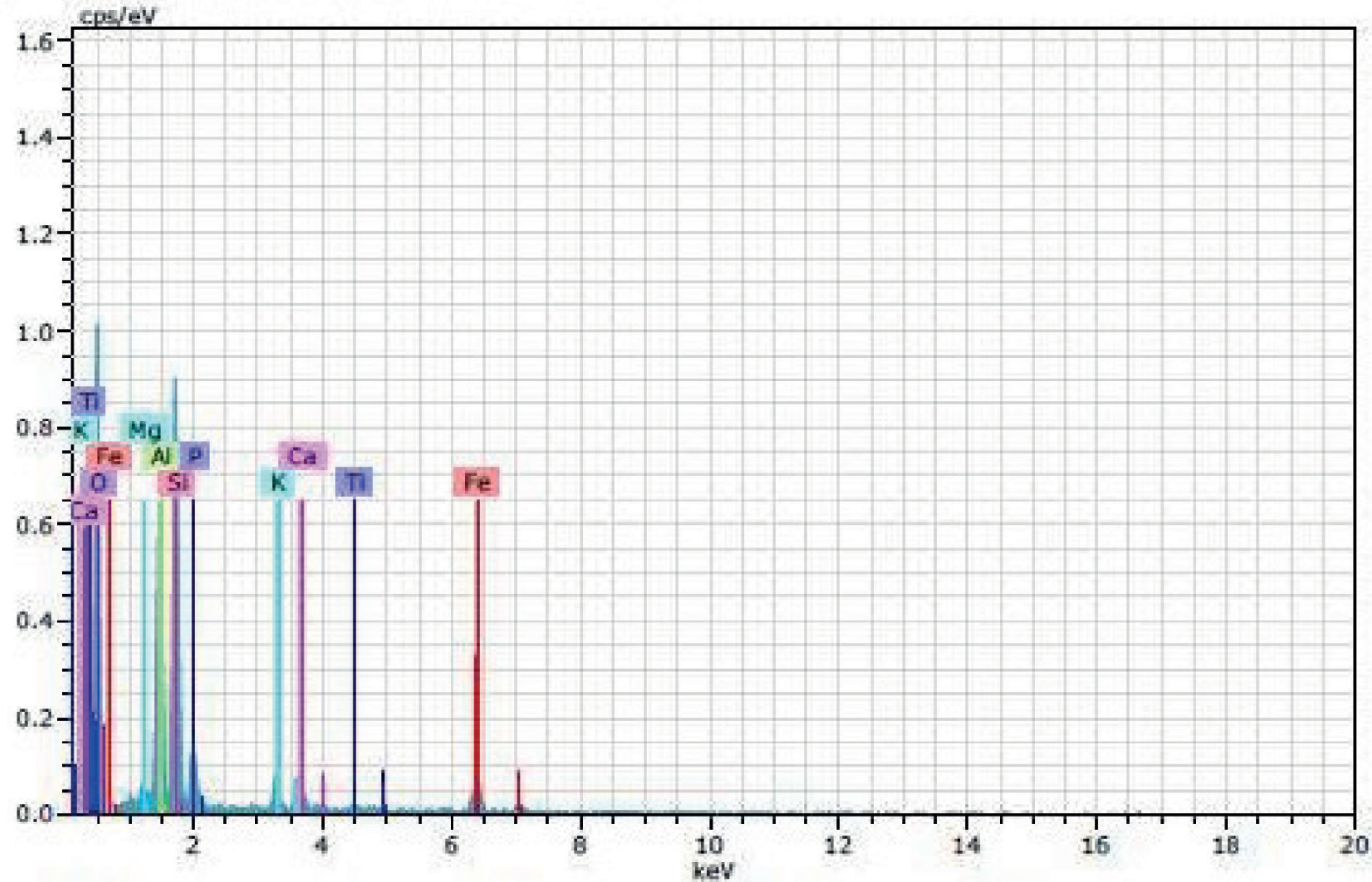

Figura 7. Fotomicrografía, espectro y composiciónde fase oxidada de hierro y titanio, principalmente. 

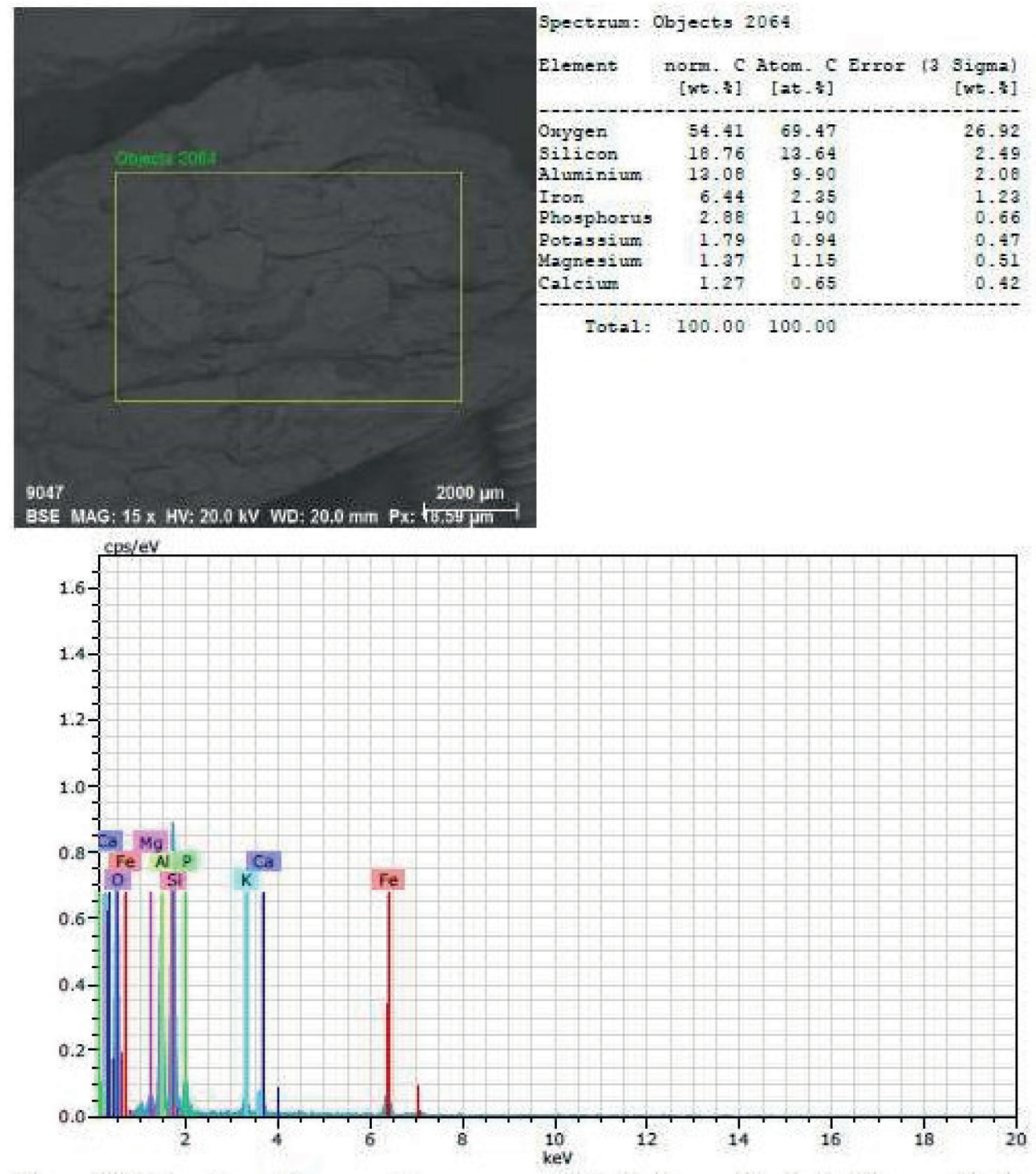

Figura 8. Fotomicrografia, espectro y composiciónde fase oxidada de hierro y titanio, principalmente. 
Figura 1. Difractograma de la Muestra Fragmento Cerámica - Sitio Arqueologico El Zapatal - Parte externa con los respectivos minerales identificados.

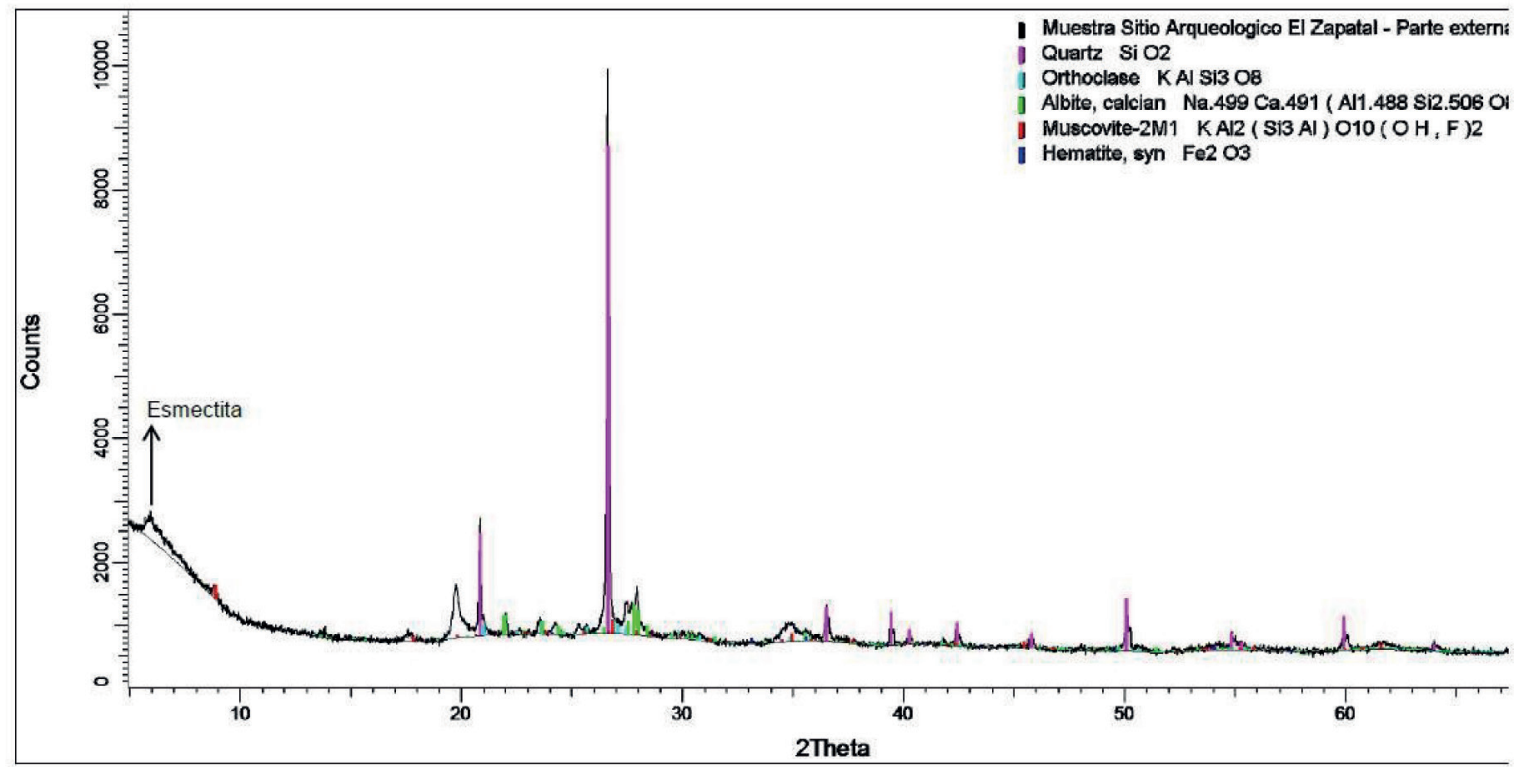

Difractograma 1. Sitio El Zapotal, Parte Externa, Loreto

Figura 2. Difractograma de la Muestra Fragmento Cerámica - Sitio Arqueologico El Zapatal - Parte interna con los respectivos minerales identificados.

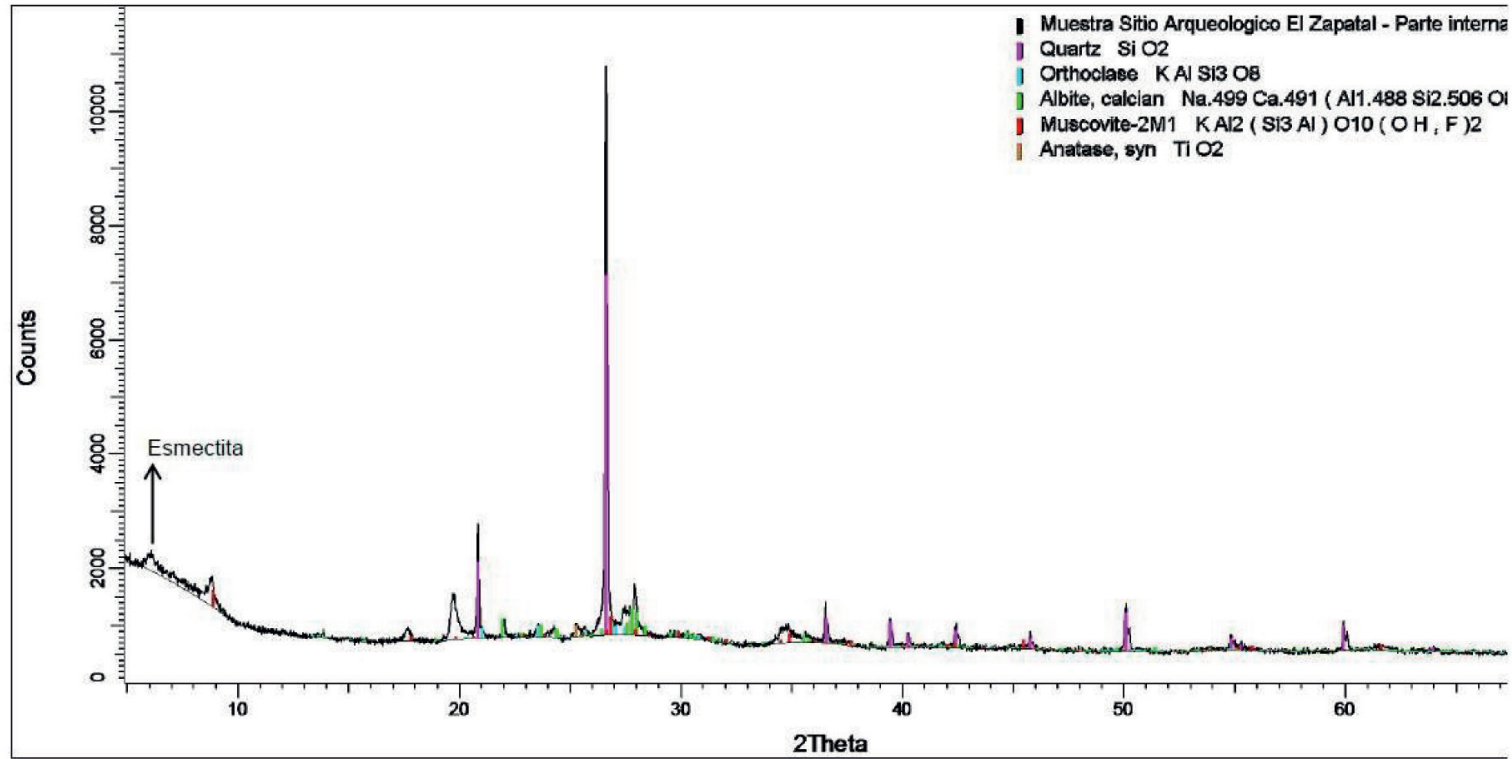

Difractograma 2. Sitio El Zapotal, Parte Interna, Loreto 


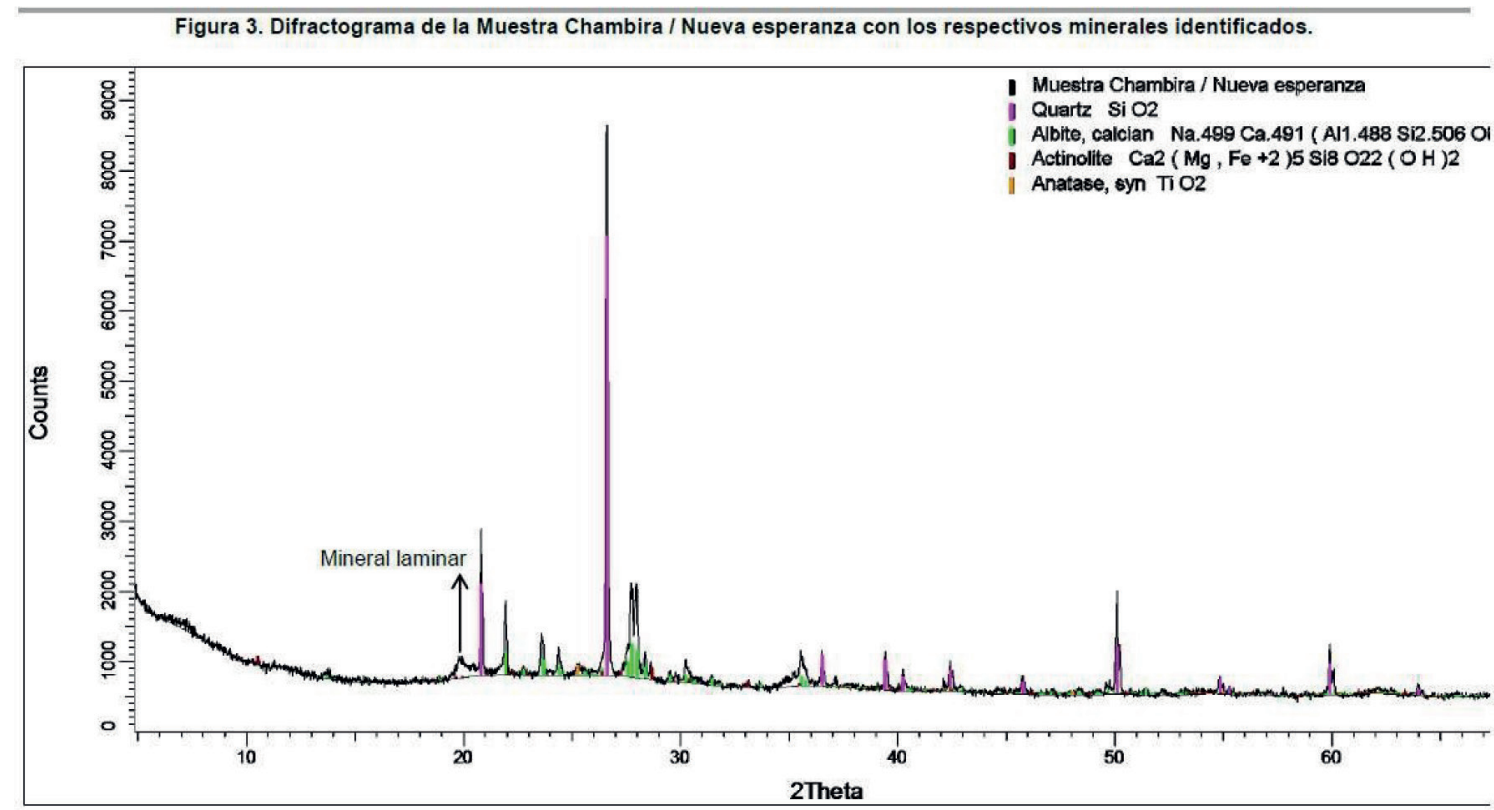

Difractograma 3. Sitio Chambira, Loreto

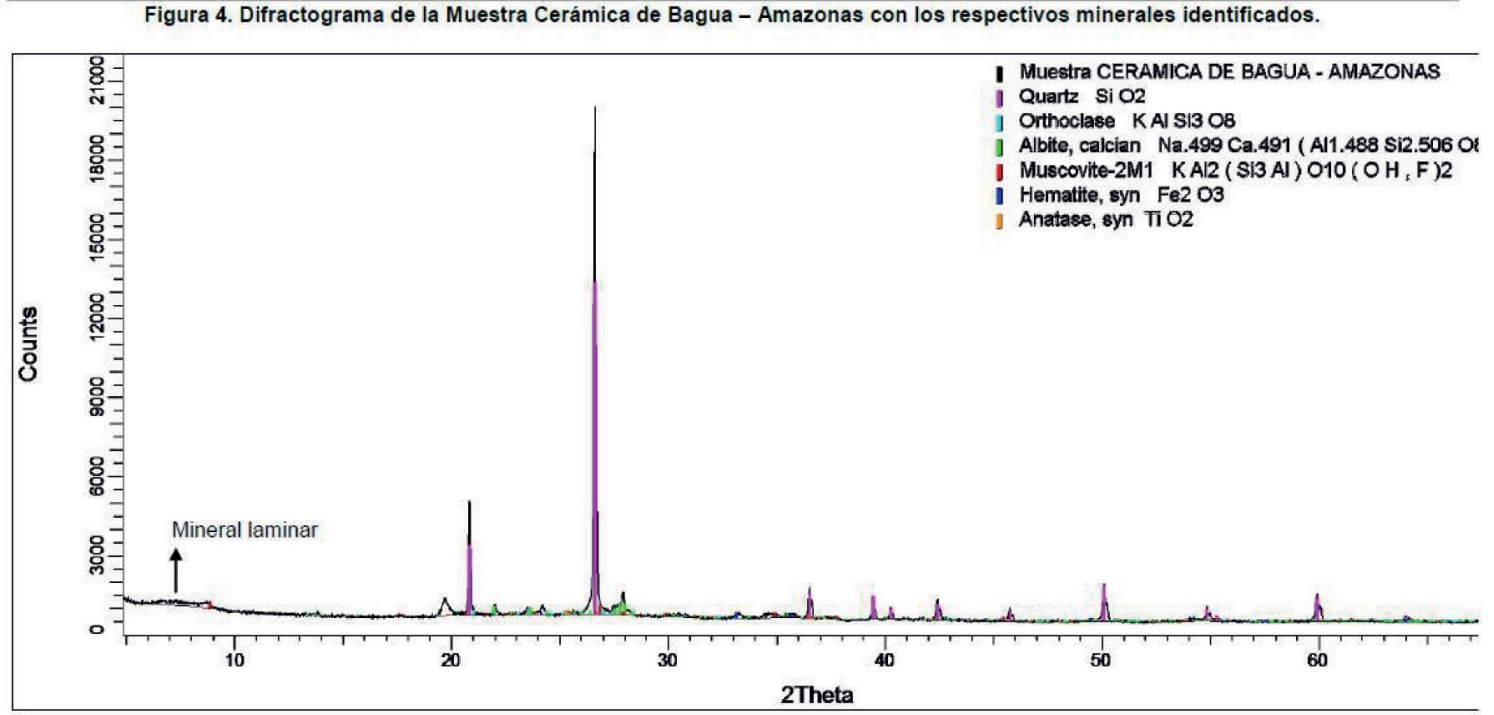

Difractograma 4. Sitio Montegrande, Jaén, Cajamarca 
Figura 5. Difractograma de la Muestra Cerámica Balsapuerto con incisiones - Loreto con los respectivos minerales identificados.

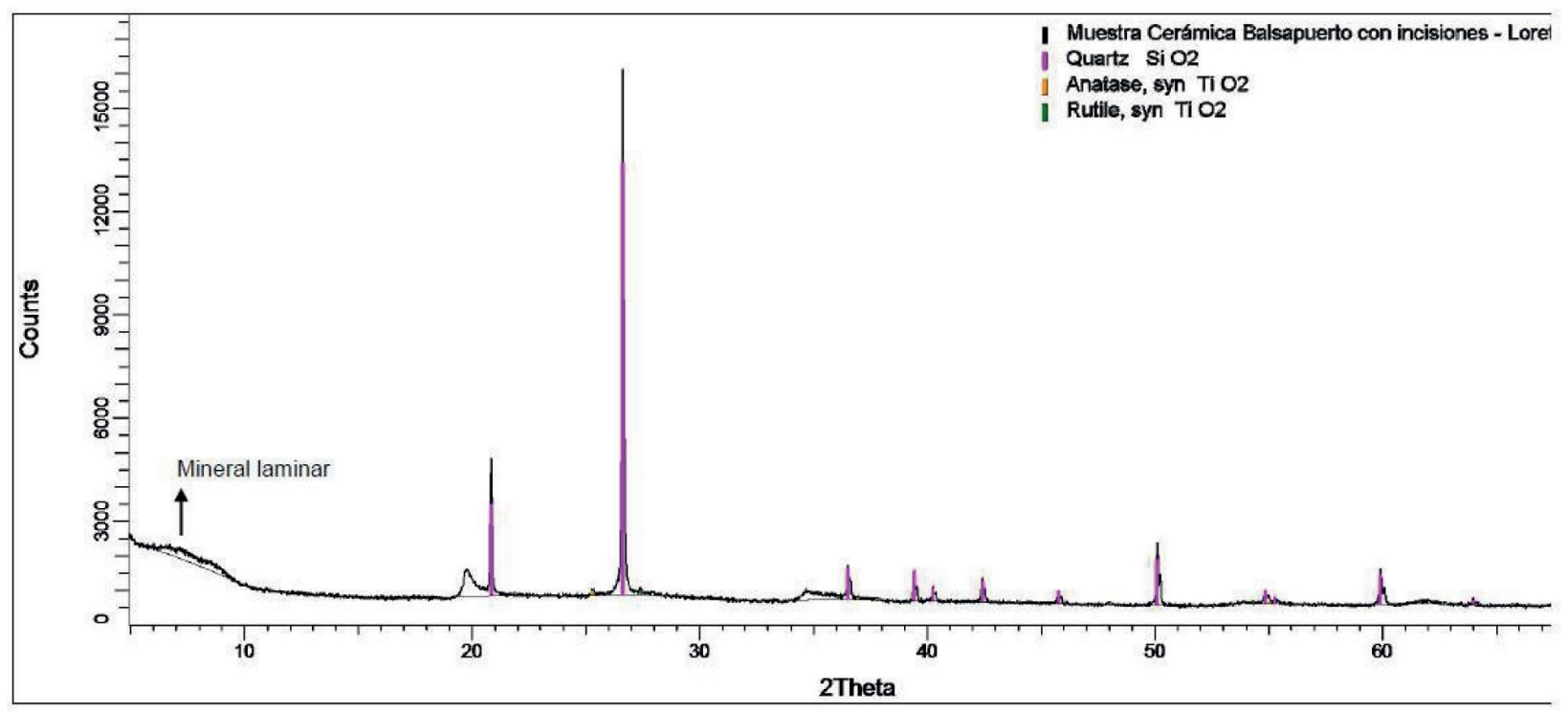

Difractografia 5. Sitio Balsapuerto, Loreto

Figura 6. Difractograma de la Muestra Cerámica de Pucharina - Junin con los respectivos minerales identificados.

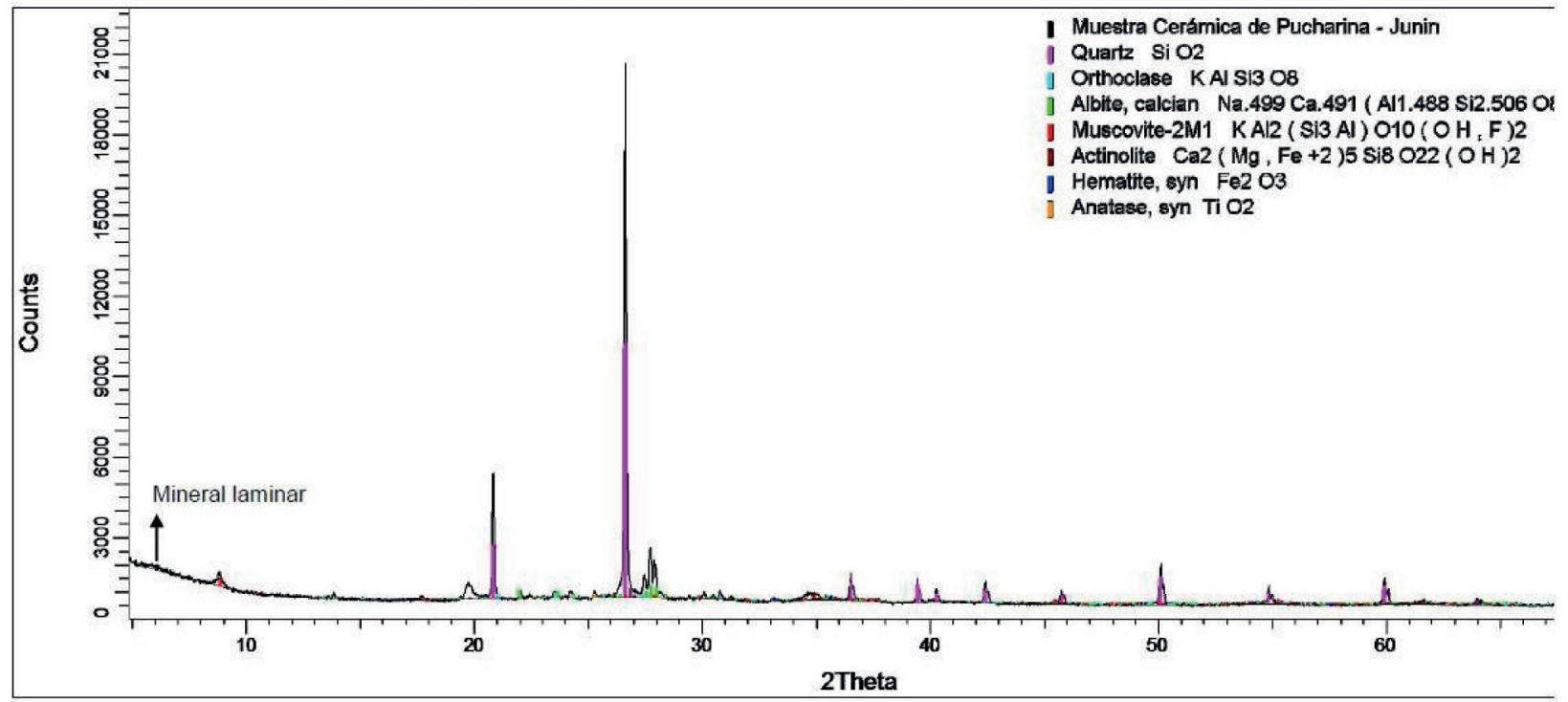

Difractografia 6. Sitio Pucharini, Junín 


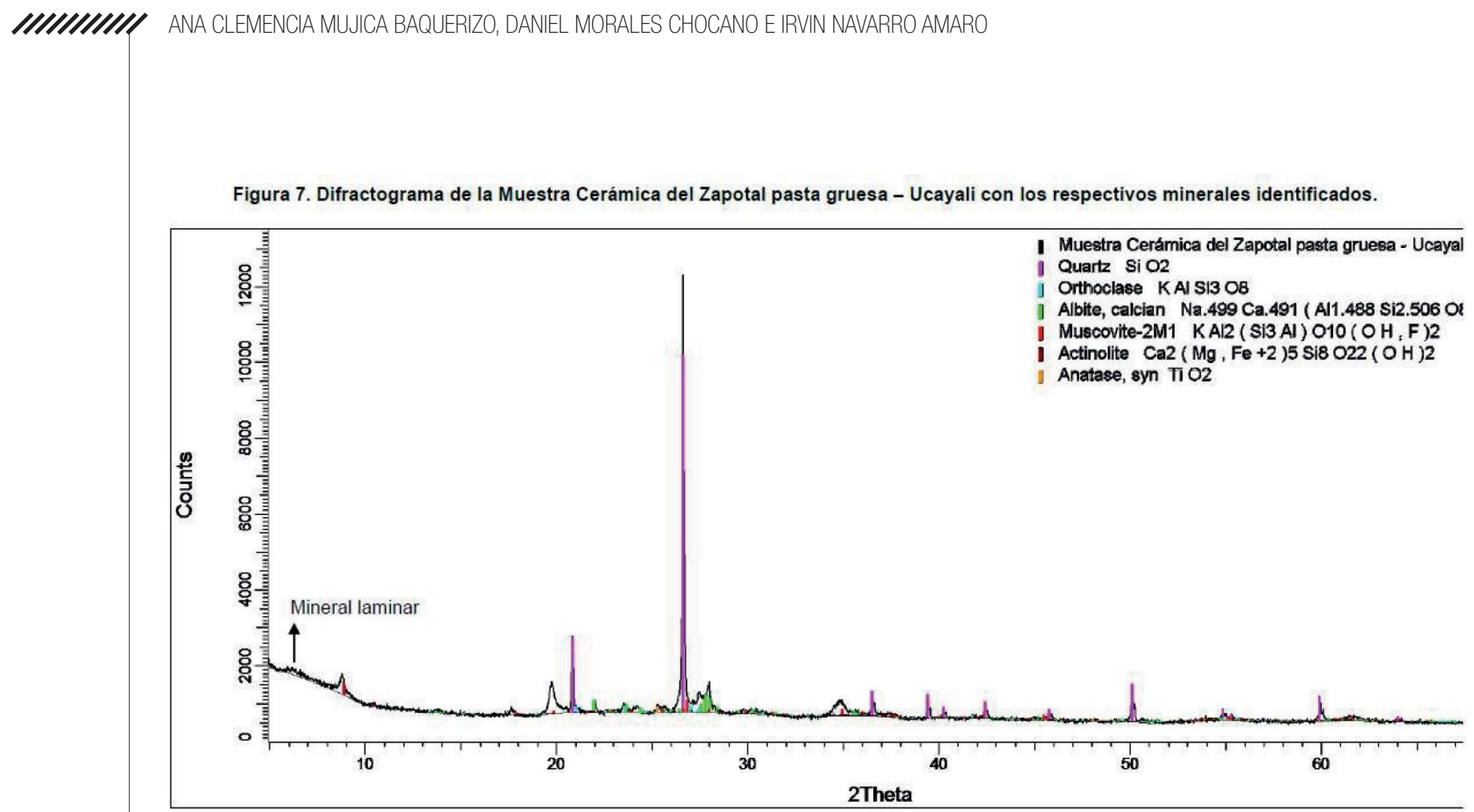

Difractografia. Sitio El Zapotal, Pasta Gruesa, Loreto 